\title{
Integral Sliding Mode Control Strategy of D-STATCOM for Unbalanced Load Compensation under Various Disturbances
}

\author{
Mingchao Xia and Yanhui Mao \\ School of Electrical Engineering, Beijing Jiaotong University, No. 3 Shang Yuan Cun, Hai Dian District, Beijing 100044, China \\ Correspondence should be addressed to Mingchao Xia; mchxia@bjtu.edu.cn
}

Received 1 July 2013; Accepted 26 August 2013

Academic Editor: Rongni Yang

Copyright (C) 2013 M. Xia and Y. Mao. This is an open access article distributed under the Creative Commons Attribution License, which permits unrestricted use, distribution, and reproduction in any medium, provided the original work is properly cited.

\begin{abstract}
Control strategies of D-STATCOM for unbalanced load compensation under internal and external disturbances were discussed. Linear control strategies do not have a satisfactory dynamic performance and become invalid under internal or external disturbances. To guarantee a good precision and robustness, a control strategy combining input-output feedback linearization technique with integral sliding mode control (ISMC) method was applied to D-STATCOM for unbalanced load compensation. The strategy has features of simple structure and is easy to implement. A 10 MVar/10 kV D-STATCOM simulation system was built in PSCAD/EMTDC to verify the effectiveness and robustness of the control strategy proposed. Simulation results show that the control strategy can compensate reactive power and eliminate unbalance simultaneously under various disturbances.
\end{abstract}

\section{Introduction}

With the fast development of modern society, requirements of good power quality become higher and higher. Unbalanced loads such as electric arc furnace and rolling mill will cause enormous impacts on power quality in the power distribution grid by unbalanced current and by absorbing a large amount of reactive power, which endanger the normal operation of the power supply and electrical equipment. In order to improve the power quality, compensating reactive power and unbalanced load current simultaneously was necessary. Distribution Static Synchronous Compensator (D-STATCOM), which has features of fast dynamic response and compact structure, can compensate reactive power and unbalanced current [1]. Many control strategies have been proposed for D-STATCOM to compensate unbalanced load, while they presented a poor performance under various disturbances.

Sliding mode control (SMC) has gained much attention for its robustness. Reference [2] presented a model reference adaptive sliding mode control algorithm for the single-phase shunt APF. The THD performance and power quality were improved by the control algorithm which was insensitive to the nonlinear load and disturbance. Reference [3] presented an adaptive variable structure control strategy for a class of uncertain switched delay systems with parameter uncertainties, unknown nonlinear perturbations, and external disturbance to adapt the unknown upper bounds of the nonlinear disturbances so that the objective of asymptotic stabilization with an $H_{\infty}$-norm bound is achieved under the hysteresis switching law. Reference [4] combined SMC with adaptive tuning for the nonlinear system with uncertain parameters. The control system was robust against parameter variation and external disturbances, the tracking capacity was guaranteed, and the upper bound of the system uncertainty was unnecessary. Reference [5] presented an adaptive fuzzy sliding mode controller (AFSMC) for linear systems with mismatched time-varying uncertainties. The available uncertainty bounds, which are necessary for the traditional SMC, were not needed, the system was stable on the sliding surface and the chattering was reduced. Reference [6] presented a robust control scheme that consists of sliding mode control, nonlinear disturbance observer, and radial basis function neural network for a class of uncertain multi-input and multioutput (MIMO) nonlinear systems with the unknown external disturbance, the system uncertainty, and the backlash-like hysteresis. The scheme 


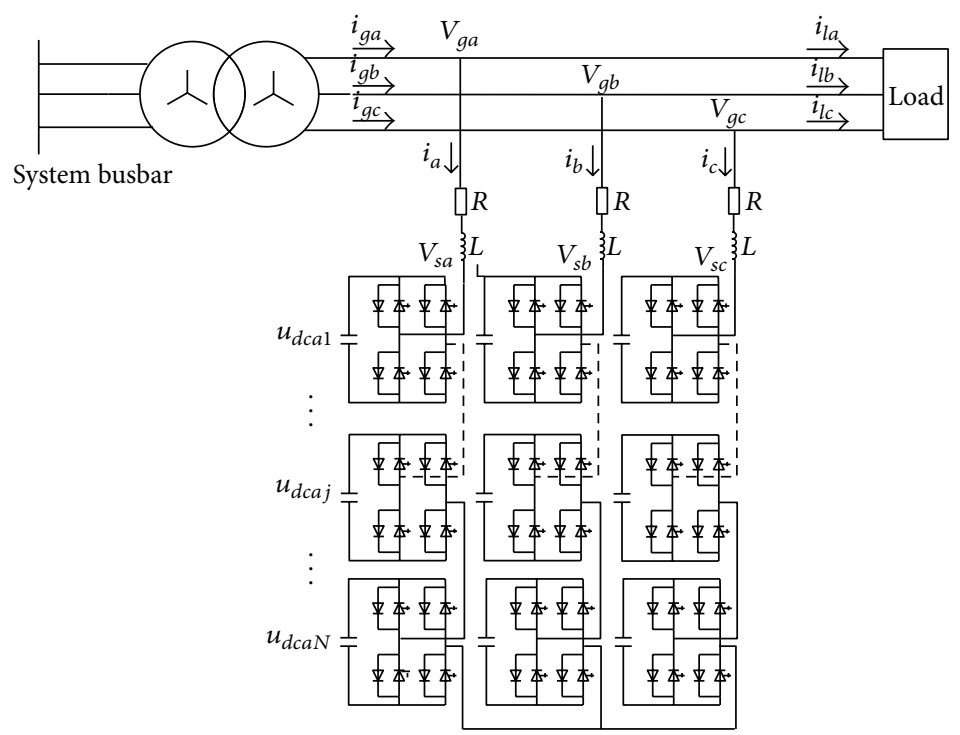

FIGURE 1: The main wiring diagram of D-STATCOM in power distribution grid.

had been successfully applied to near-space vehicles attitude dynamics. Reference [7] presented a proportional-integraldifferential neural network-based sliding mode controller for modular multilevel high-voltage DC converter of offshore wind power, which could make the system globally stable and achieve a stronger robustness. Reference [8] presented a terminal SMC based on adaptive fuzzy-neural observer for the nonaffine nonlinear uncertain system, where only the measurable outputs were necessary. Reference [9] presented a robust input-output sliding mode control method for the buck converter that avoided state measurements, or the use of observers. Reference [10] presented an ISMC-based ASMC algorithm for rigid spacecraft attitude maneuvers, which could reduce switching gain and chattering and get a faster convergence rate. Reference [11] combined the inputoutput linearization technique with the integral sliding mode for load pressure control of die-cushion cylinder drive in the presence of unknown disturbances and parametrical uncertainties. Conducted tests showed a very good and robust performance of the closed loop control. Reference [12] combined rate reaching law with integral sliding manifold to form a novel integral sliding mode controller which was suitable for many nonlinear systems with approximate mathematics model, especially with unmatched uncertainty or external disturbance, and had better performance in rapidity, stationarity, and robustness. Reference [13] presented a robust integral sliding mode control method for a class of uncertain switched nonlinear systems, by which the state of the system remained on the integral sliding surface from the initial time. Reference [14] presented a new PD sliding mode observer to construct the accurate estimations for both system states and sensor faults simultaneously for Lipschitz nonlinear and Markovian jump systems with time delay subject to sensor faults. Based on the state estimation, an observer-based faulttolerant state-feedback controller is designed to stabilize the resulting closed-loop system.
As SMC has a good robustness against the disturbances and has been applied to many applications, it can be applied to D-STATCOM for unbalanced load compensation so that the performance of D-STATCOM under various disturbances will be improved. This paper proposes a control strategy combining integral sliding mode control with input-output feedback linearization for the compensation of unbalanced load. Two loops are designed: one is for the positive sequence compensation where the positive sequence reactive power is compensated and the other is for the negative sequence compensation where the negative sequence current due to load unbalance is compensated. ISMC combined with inputoutput feedback linearization is used in the two loops. The advantages of the proposed control strategy are tripartite. First, the steady-state error in the presence of disturbances is avoided by ISMC. Second, asymptotic state observers are not need. Third, the two-loop control form makes it possible to compensate positive sequence reactive power and negative sequence current separately to improve power quality. A $10 \mathrm{MVar} / 10 \mathrm{kV}$ D-STATCOM simulation system was built in PSCAD/EMTDC. Simulation results proved that the control strategy works well under unbalanced condition and compensates reactive power and negative sequence current simultaneously in the presence of disturbances.

\section{The Mathematical Model of D-STATCOM under Unbalanced Load}

As shown in Figure $1, V_{g}$ and $i_{g}$ represent the grid voltage and current; $V_{s}$ and $i$ represents the output voltage and current of D-STATCOM; $i_{l}$ represent the load current; $u_{\mathrm{dc}}$ represents the DC voltage of each capacitor where " $a$ ", " $b$," and " $c$ " in subscript represent the three phases of phase $a$, phase $b$, and phase $c$; $L$ represents the connection inductance; $R$ represents 
the resistance and the inverter loss. The mathematical model of D-STATCOM in the static three-phase coordinates is

$$
\begin{aligned}
& L \frac{d i_{a}(t)}{d t}=V_{g a}(t)-V_{s a}(t)-R i_{a}(t), \\
& L \frac{d i_{b}(t)}{d t}=V_{g b}(t)-V_{s b}(t)-R i_{b}(t), \\
& L \frac{d i_{c}(t)}{d t}=V_{g c}(t)-V_{s c}(t)-R i_{c}(t) .
\end{aligned}
$$

The dq transformation is usually used for three-phase analysis, and the sequence component decomposition is usually used for unbalance analysis. When compensating unbalanced load, it would be better to compensate positive sequence reactive power and negative sequence current separately. According to sequence component decomposition, D-STATCOM can be equivalent to a positive sequence one and a negative one, where both of them are independent. This is the basis of the control strategy proposed. The positive and negative sequence models are as (2) and (3):

$$
L \frac{d}{d t}\left[\begin{array}{l}
i_{d P} \\
i_{q P}
\end{array}\right]=\left[\begin{array}{l}
V_{d P} \\
V_{q P}
\end{array}\right]+\left[\begin{array}{ccc}
-R & \omega^{P} L & -M^{P} \cos \delta^{P} \\
-\omega^{P} L & -R & -M^{P} \sin \delta^{P}
\end{array}\right] *\left[\begin{array}{c}
i_{d P} \\
i_{q P} \\
u_{\mathrm{dc}}
\end{array}\right]
$$

$$
\begin{aligned}
& L \frac{d}{d t}\left[\begin{array}{l}
i_{d N} \\
i_{q N}
\end{array}\right] \\
& \quad=\left[\begin{array}{l}
V_{d N} \\
V_{q N}
\end{array}\right]+\left[\begin{array}{ccc}
-R & \omega^{N} L & -M^{N} \cos \delta^{N} \\
-\omega^{N} L & -R & -M^{N} \sin \delta^{N}
\end{array}\right] *\left[\begin{array}{l}
i_{d N} \\
i_{q N} \\
u_{\mathrm{dc}}
\end{array}\right],
\end{aligned}
$$

where $i_{d P}, i_{q P}, i_{d N}, i_{q N}$ represent the $d$ and $q$ components of the output positive $(P)$ and negative $(N)$ sequence currents of D-STATCOM; $V_{d P}, V_{q P}, V_{d N}, V_{q N}$ represent the $d$ and $q$ components of the positive $(P)$ and negative $(N)$ sequence grid voltage; $\omega^{P}, \omega^{N}$ represent the positive $(P)$ and negative $(N)$ sequence angular speed; $M^{P}, M^{N}$ represent the positive $(P)$ and negative $(N)$ sequence modulation ratio; $\delta^{P}, \delta^{N}$ represent the positive $(P)$ and negative $(N)$ sequence phase difference between the grid voltage and the output voltage of D-STATCOM.

\section{The Control Strategy for Unbalanced Load Compensation}

Unbalanced load compensation is a prominent problem for D-STATCOM both in theory and practice. Reference [15] compensated the positive sequence component of reactive power and negative sequence current in a way that the duty ratio and the input phase currents satisfy a special relationship. Reference [16] treated STATCOM as three single-phase systems for unbalance compensation. Reference [17] employed the feed forward compensation scheme with symmetrical components method to compensate unbalanced load. Reference [18] compensated unbalanced network fault and load by separate control of positive and negative sequence current with switching function modulation. Reference [19] combined linear PID feedback control with the admittance compensation method to compensate unbalanced load. Reference [20] presented a software sensor-based control strategy to compensate unbalanced load avoiding the use of the physical voltage sensors.

However, the common drawbacks of the above mentioned control strategies are heavily reliant on the mathematical model and sensitive to disturbances. Considering the drawbacks, it is worth applying SMC to D-STATCOM which is independent of the mathematical model and robust against disturbances. Some works have applied SMC to DSTATCOM to compensate reactive power [21-26]. But all of them cannot compensate unbalanced load.

This paper aims to apply a control strategy based on integral sliding mode control to D-STATCOM to compensate unbalanced load under various disturbances. Since the mathematical model of D-STATCOM under unbalanced condition includes a positive sequence part and a negative sequence part, the separate control of positive and negative sequence currents can be achieved. Then, the integral sliding mode control combined with the input-output feedback linearization is used in the two parts to compensate positive sequence reactive power and negative sequence current simultaneously. The entire schematic diagram of the control strategy is as shown in Figure 2, where $i_{d P \text { ref }}$ represents the current used to stabilize DC voltage, $i_{q P \_l o a d}$ represents the positive sequence reactive load current, and $i_{d N \text { load }}$ and $i_{q N \_ \text {load }}$ represent the negative sequence load current.

3.1. The Implementation of Input-Output Feedback Linearization. D-STATCOM is a multivariable, strong coupling, nonlinear system which is complicated to design control strategy. The input-output feedback linearization is a straightforward method to simplify such nonlinear system. The main idea of this method is to linearize and decouple the original system into a pseudo linear system through coordinate transformation which is realized by the differential geometric theory. The control characteristics of the system remain unchanged since the coordinate transformation is diffeomorphism. First, input-output feedback linearization method is applied to the positive sequence mathematical model as in (2): the state variables are $X=\left[x_{1}, x_{2}\right]^{T}=\left[i_{d p}, i_{q p}\right]^{T}$, the control variables are $U=\left[u_{1}, u_{2}\right]^{T}=\left[M^{P} \cos \delta^{P}, M^{P} \sin \delta^{P}\right]^{T}$, and the output variables are $Y=\left[y_{1}, y_{2}\right]^{T}=\left[i_{d p}, i_{q p}\right]^{T}$. The positive sequence mathematical model and the output equation can be equivalent to (4) and (5), respectively,

$$
\begin{gathered}
{\left[\begin{array}{c}
\dot{x} \\
x_{1} \\
x_{2}
\end{array}\right]=\left[\begin{array}{c}
-\frac{R}{L} x_{1}+\omega^{P} x_{2}+\frac{V_{d P}}{L} \\
-\omega^{P} x_{1}-\frac{R}{L} x_{2}
\end{array}\right]+\left[\begin{array}{cc}
-\frac{u_{\mathrm{dc}}}{L} & 0 \\
0 & -\frac{u_{\mathrm{dc}}}{L}
\end{array}\right] *\left[\begin{array}{l}
u_{1} \\
u_{2}
\end{array}\right]} \\
y_{1}=h_{1}(x)=x_{1} \\
y_{2}=h_{2}(x)=x_{2}
\end{gathered}
$$




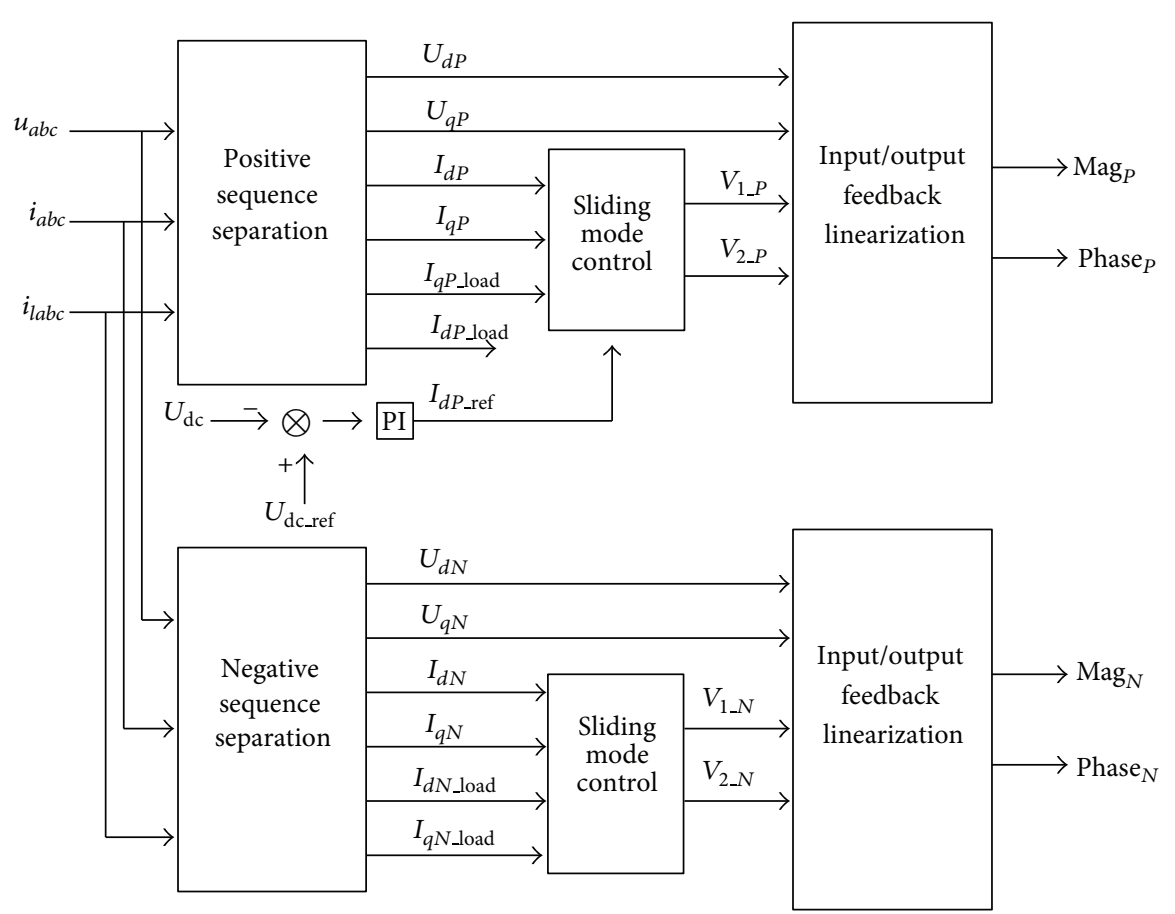

Figure 2: The entire schematic diagram of the control strategy.

Equation (6) can be deduced from (4) and (5):

$$
\left[\begin{array}{c}
\cdot \\
y_{1} \\
\cdot \\
y_{2}
\end{array}\right]=A(X)+E(X)\left[\begin{array}{l}
u_{1} \\
u_{2}
\end{array}\right]
$$

where

$$
\begin{gathered}
A(X)=\left[\begin{array}{c}
-\frac{R}{L} x_{1}+\omega^{P} x_{2}+\frac{V_{d P}}{L} \\
-\omega^{P} x_{1}-\frac{R}{L} x_{2}
\end{array}\right], \\
E(X)=\left[\begin{array}{cc}
-\frac{u_{\mathrm{dc}}}{L} & 0 \\
0 & -\frac{u_{\mathrm{dc}}}{L}
\end{array}\right] .
\end{gathered}
$$

Two new input variables named $v_{1 \_P}$ and $v_{2 P}$ are introduced to linearize and decouple the positive sequence mathematical model, where the relations of $v_{1 \_}, v_{2} P$, and $u_{1}, u_{2}$ are as follows:

$$
\left[\begin{array}{l}
u_{1} \\
u_{2}
\end{array}\right]=E(X)^{-1}\left[-A(X)+\left[\begin{array}{l}
v_{1 \_} P \\
v_{2} P
\end{array}\right]\right] .
$$

The final form of the model is as follows:

$$
\left[\begin{array}{l}
\cdot \\
y_{1} \\
\cdot \\
y_{2}
\end{array}\right]=\left[\begin{array}{l}
v_{1 \_} \\
v_{2 P}
\end{array}\right]
$$

The DC voltage control of capacitors in series D-STATCOM is an internal dynamic system control issue. For the stability of the internal dynamic system, the three-level DC voltage control strategy as in [27] was adopted. Since the positive and negative sequence mathematical models have the same form, the negative sequence model can be equivalent to (10) and (11):

$$
\begin{gathered}
{\left[\begin{array}{c}
\cdot \\
y_{3} \\
\cdot \\
y_{4}
\end{array}\right]=\left[\begin{array}{l}
v_{1 \_N} \\
v_{2 \perp N}
\end{array}\right],} \\
{\left[\begin{array}{l}
u_{3} \\
u_{4}
\end{array}\right]=E(X)^{-1}\left[-B(X)+\left[\begin{array}{l}
v_{1 \_N} \\
v_{2-N}
\end{array}\right]\right],}
\end{gathered}
$$

where $\left[x_{3}, x_{4}\right]^{T}=\left[i_{d N}, i_{q N}\right]^{T},\left[u_{3}, u_{4}\right]^{T}=$ $\left[M^{N} \cos \delta^{N}, M^{N} \sin \delta^{N}\right]^{T},\left[y_{3}, y_{4}\right]^{T}=\left[i_{d N}, i_{q N}\right]^{T}$.

$$
B(X)=\left[\begin{array}{c}
-\frac{R}{L} x_{3}+\omega^{N} x_{4}+\frac{V_{d N}}{L} \\
-\omega^{N} x_{3}-\frac{R}{L} x_{4}
\end{array}\right] .
$$

3.2. The Implementation of Integral Sliding Mode Control. Theoretically, the input-output feedback linearization is a relatively uncomplicated way to control D-STATCOM. Unfortunately, this control is also highly sensitive to disturbances, which in practice considerably restricts its performances. The sliding mode control has been widely applied because of its satisfactory operation characteristics such as fastness, robustness, and stability. A control strategy based on inputoutput linearization and SMC, which can considerably simplify the design progress and increase the overall system robustness, was proposed to guarantee the normal operation 
of D-STATCOM and compensate positive sequence reactive power and negative sequence current.

We define the tracking error named $e$ as follows:

$$
\begin{gathered}
e_{1}=i_{d P}-i_{d P \mathrm{ref}}, \\
e_{2}=i_{q P}-i_{q P \_\mathrm{load}}, \\
e_{3}=i_{d N}-i_{d N \_l o a d}, \\
e_{4}=i_{q N}-i_{q N \_\mathrm{load}} .
\end{gathered}
$$

Determining a sliding surface is the key of sliding mode control. While tracking the reference current, traditional SMC such as in [21-23] cannot avoid steady state error in the presence of disturbances. In this paper, an integral portion is added to the traditional SMC to solve this problem. The switch function can be described as follows:

$$
\begin{aligned}
& S_{1}=k_{11} \times e_{1}+k_{12} \times \int e_{1}, \\
& S_{2}=k_{21} \times e_{2}+k_{22} \times \int e_{2}, \\
& S_{3}=k_{31} \times e_{3}+k_{32} \times \int e_{3}, \\
& S_{4}=k_{41} \times e_{4}+k_{42} \times \int e_{4} .
\end{aligned}
$$

In order to weaken the chattering and improve the convergence, exponential approach law is used in this paper as follows:

$$
\begin{aligned}
& \dot{S_{1}}=-\varepsilon_{1} \operatorname{sgn}\left(S_{1}\right)-k_{1} S_{1}, \\
& \dot{S_{2}}=-\varepsilon_{2} \operatorname{sgn}\left(S_{2}\right)-k_{2} S_{2}, \\
& \dot{S_{3}}=-\varepsilon_{3} \operatorname{sgn}\left(S_{3}\right)-k_{3} S_{3}, \\
& \dot{S_{4}}=-\varepsilon_{4} \operatorname{sgn}\left(S_{4}\right)-k_{4} S_{4},
\end{aligned}
$$

From (9), (10), and (15), we can obtain

$$
\begin{aligned}
& v_{1 \_}=-\varepsilon_{1} \operatorname{sgn}\left(S_{1}\right)-k_{1} S_{1}, \\
& v_{2 \_}=-\varepsilon_{2} \operatorname{sgn}\left(S_{2}\right)-k_{2} S_{2}, \\
& v_{1 \_N}=-\varepsilon_{3} \operatorname{sgn}\left(S_{3}\right)-k_{3} S_{3}, \\
& v_{2 \_N}=-\varepsilon_{4} \operatorname{sgn}\left(S_{4}\right)-k_{4} S_{4} .
\end{aligned}
$$

Finally, from (8), (11), and (16), we get the control variables $u_{1}, u_{2}, u_{3}$, and $u_{4}$ which are applied to generate PWM pulse signals to control IGBTs in D-STATCOM.

\section{Simulation}

In order to verify the effectiveness of the control strategy proposed in this paper, a $10 \mathrm{MVar} / 10 \mathrm{kV}$ D-STATCOM simulation system was built in PSCAD/EMTDC. The system parameters are the rated line voltage at the point of common coupling: $V_{g}=10 \mathrm{kV}$; the impedance of the power supply and the line: $Z_{s}=0.015+j 0.32 \times 10^{3} \Omega$. The parameters of D-STATCOM are the joint inductance: $L=3.18 \times 10^{-3} \mathrm{H}$; the single capacitor in DC side: $C=6.2 \mathrm{mF}$; the cascade count: $N=12$. The equivalent loss resistance between $\mathrm{D}$ STATCOM and the point of common coupling is $R=0.5 \Omega$. The load of phase $A$ is $Z_{a}=5+j 0.003 \Omega$; the load of phase $B$ is $Z_{b}=4.5+j 0.003 \Omega$; the load of phase $C$ is $Z_{c}=$ $4+j 0.003 \Omega$. The unbalanced degree of power grid current is $\Delta I_{s} \%=\left[\left(I_{s \max }-I_{s \min }\right) / I_{s \text { ave }}\right] \times 100 \%$, where $I_{s \max }$ represents the maximum value of the three-phase current peak, $I_{s \text { min }}$ represents the minimum value of the three-phase current peak, and $I_{s \text { ave }}$ represents the average value of the three-phase current peak.

Figure 3 shows the reactive power compensation effect when there were no disturbances. The reactive power compensation effect of the ISMC is shown in Figure 3(a), where the reactive power in grid (Q_grid) fell to 0.0 Mvar from 4.3 Mvar at $0.4 \mathrm{~s}$ when the control strategy was put into operation and fluctuated a little at $1.0 \mathrm{~s}$ and became stable at $1.2 \mathrm{~s}$ due to the DC voltages in the three phases that were forced to $1 \mathrm{kV}$. The reactive power generated by $\mathrm{D}$ STATCOM (Q_STATCOM) could track the reactive power in load to guarantee the Q_grid to be stable at $0.0 \mathrm{Mvar}$ and the voltage at the point of common coupling rose to $10.0 \mathrm{kV}$ from $9.7 \mathrm{kV}$. This proved that the positive sequence control loop could make D-STATCOM generate reactive power needed by load to improve the power factor and voltage at the point of common coupling. The reactive power compensation effect of the traditional SMC is shown in Figure $3(\mathrm{~b})$, where the overshoot in the transient process is larger than ISMC. This proved that the integral portion can improve the compensation performance.

Figure 4 shows the negative sequence current compensation effect of D-STATCOM under no disturbances. The threephase grid current before the control strategy was put into operation is shown in Figure $4(\mathrm{a})$, where $I_{a_{\text {-grid }}}=1.641 \mathrm{kA}$, $I_{b_{\text {grid }}}=1.778 \mathrm{kA}, I_{c_{\text {-grid }}}=1.820 \mathrm{kA}$, and $\Delta I_{s} \%=10.25 \%$. The unbalance compensation effect of the ISMC is shown in Figure $4(\mathrm{~b})$, where $I_{a_{\text {-grid }}}=1.738 \mathrm{kA}, I_{b_{\text {-grid }}}=1.737 \mathrm{kA}$, $I_{c_{-} \text {grid }}=1.737 \mathrm{kA}$, and $\Delta I_{s} \%=0.058 \%$. The three-phase grid current became stable and balanced due to the negative sequence control loop which made D-STATCOM generate negative sequence current needed by load to avoid the unbalance thatappeared in grid. The unbalance compensation effect of the traditional SMC is shown in Figure 4(c), where $I_{a_{\text {-grid }}}=1.735 \mathrm{kA}, I_{b_{\text {_grid }}}=1.752 \mathrm{kA}, I_{c_{\text {-grid }}}=1.722 \mathrm{kA}$, and $\Delta I_{s} \%=1.73 \%$. This proved that the integral portion can improve the compensation performance.

Figure 5 shows the reactive power compensation effect of D-STATCOM under internal disturbances containing parameter and joint impedance variation. The reactive power compensation effect of the ISMC is shown in Figure 5(a), where Q_grid and Q_DSTATCOM were quickly stable after a small fluctuation when parameter variation happened at $1.3 \mathrm{~s}$ and joint impedance variation happened at $1.6 \mathrm{~s}$, while V_pcc, kept at $10.0 \mathrm{kV}$ no matter what disturbance happened. This proved that the positive sequence control loop which contains 

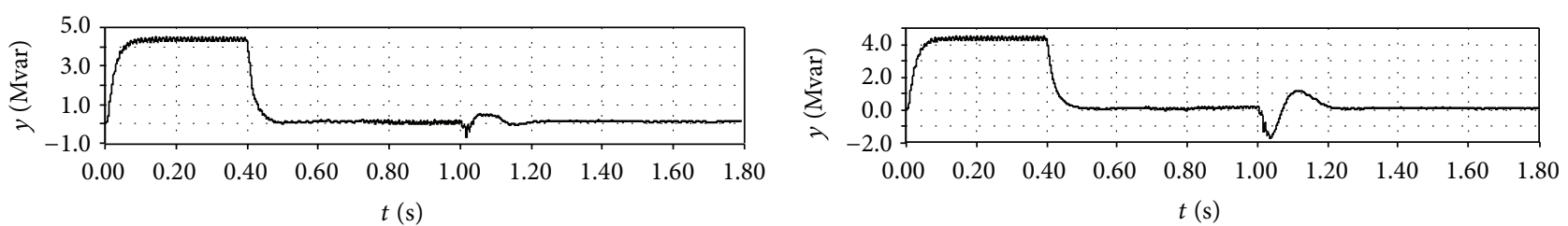

- Q_grid
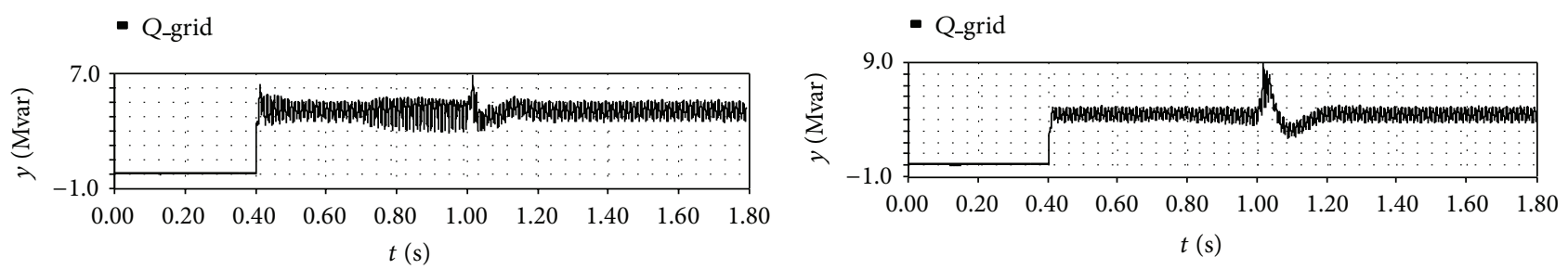

- Q_DSTATCOM

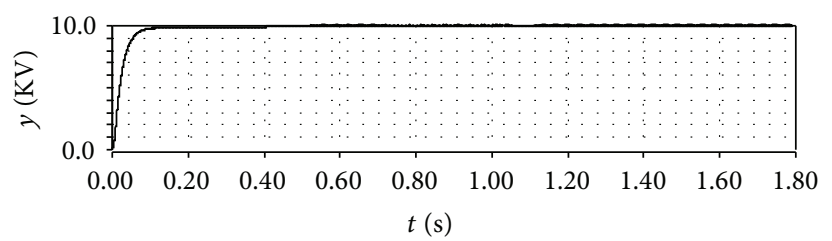

- V_pcc

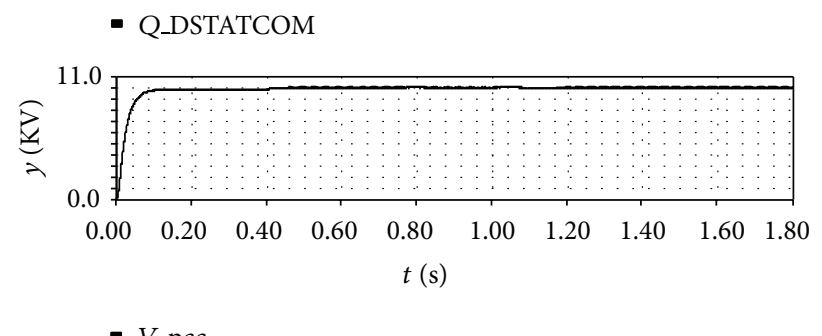

- V_pcc

(a)

(b)

FIGURE 3: The reactive power compensation effect of D-STATCOM under no disturbances.

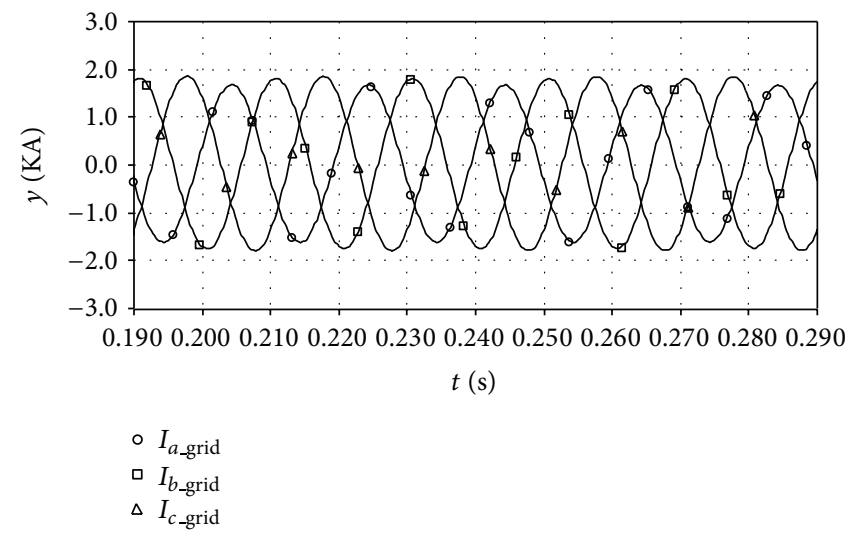

(a)

$t(\mathrm{~s})$

$\circ I_{a \_ \text {grid }}$
$\square I_{b \text { grid }}$
$\Delta I_{c \text { _grid }}$

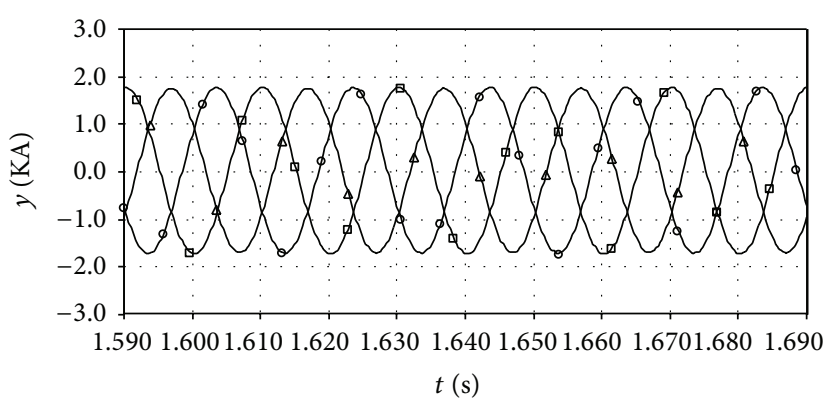

- $I_{a \text {-grid }}$

- $I_{b \text {-grid }}$

$\Delta I_{c \text {-grid }}$

(b)

(c)

FIGURE 4: The negative sequence current compensation effect of D-STATCOM under no disturbances. 

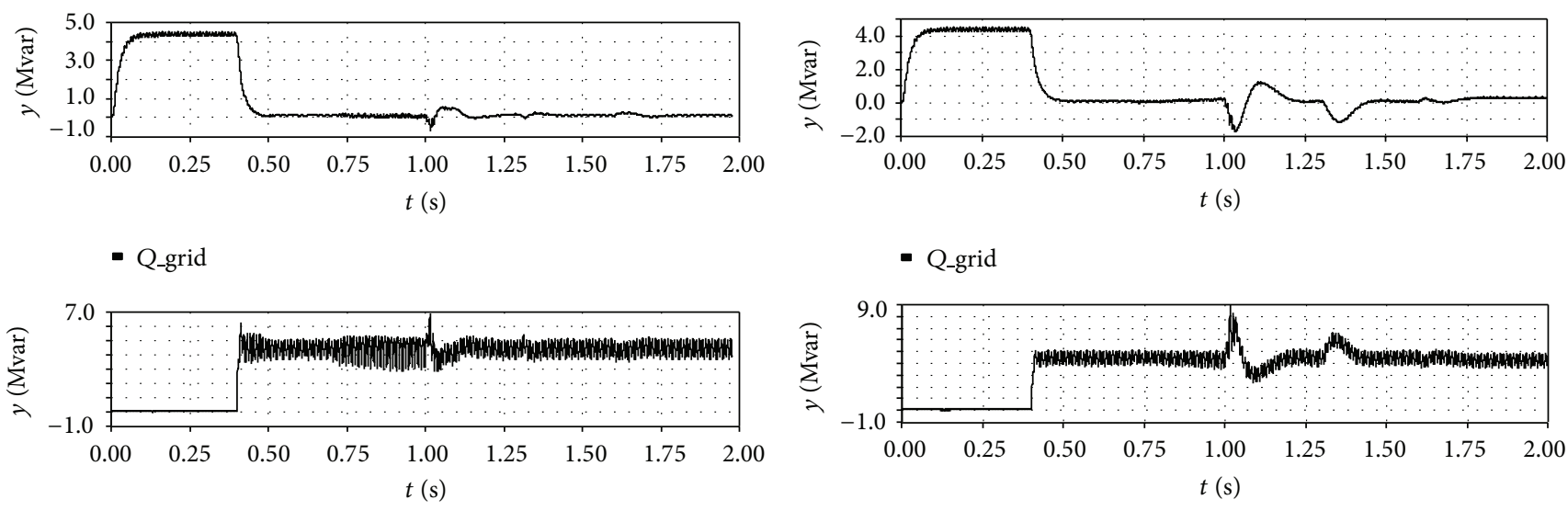

- Q_DSTATCOM

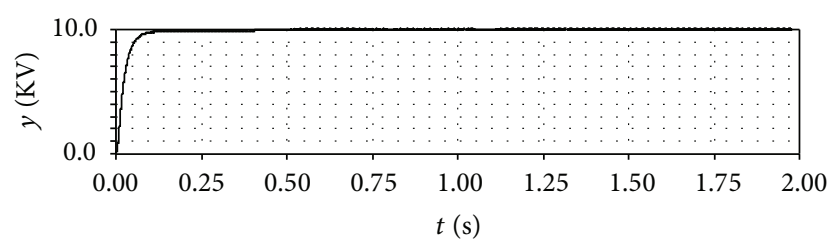

- $V_{-p c c}$

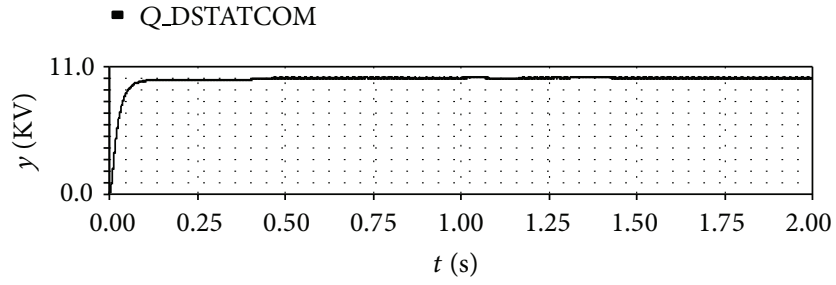

- V_pcc

(a)

(b)

FIGURE 5: The reactive power compensation effect of D-STATCOM under internal disturbances.

integral SMC can compensate reactive power needed by load and has a good robustness against internal disturbances. The reactive power compensation effect of the traditional SMC is shown in Figure 5(b), where the overshoot when the internal disturbances happened is larger than the ISMC. This proved that the integral portion can improve the robustness against the internal disturbances.

Figure 6 shows the negative sequence current compensation effect of D-STATCOM under internal disturbances. The unbalance compensation effect of the ISMC under parameter variation that happened at $1.3 \mathrm{~s}$ is shown in (a), where the three-phase grid current balanced again at $1.36 \mathrm{~s}$ with smooth transient process and $I_{a_{\text {_grid }}}=1.740 \mathrm{kA}, I_{b_{\text {_grid }}}=$ $1.737 \mathrm{kA}, I_{c_{\text {-grid }}}=1.738 \mathrm{kA}$, and $\Delta I_{s} \%=0.17 \%$, while the unbalance compensation effect of the traditional SMC is shown in Figure 6(b) where $I_{a_{- \text {grid }}}=1.729 \mathrm{kA}, I_{b_{\text {_grid }}}=$ $1.768 \mathrm{kA}, I_{c_{-} \text {grid }}=1.712 \mathrm{kA}$, and $\Delta I_{s} \%=3.23 \%$. The unbalance compensation effect of the ISMC under parameter and joint impedance variation that happened at $1.3 \mathrm{~s}$ and $1.6 \mathrm{~s}$, respectively, is shown in Figure 6(c) where the three-phase grid current balance again at $1.65 \mathrm{~s}$ with smooth transient process and $I_{a_{\text {_grid }}}=1.764 \mathrm{kA}, I_{b_{\text {_grid }}}=1.766 \mathrm{kA}, I_{c_{\text {_grid }}}=$ $1.765 \mathrm{kA}$, and $\Delta I_{s} \%=0.11 \%$, while the unbalance compensation effect of the traditional SMC is shown in Figure 6(d) where $I_{a_{\text {_grid }}}=1.751 \mathrm{kA}, I_{b_{\text {_grid }}}=1.790 \mathrm{kA}, I_{c_{\text {_grid }}}=$ $1.763 \mathrm{kA}$, and $\Delta I_{s} \%=1.64 \%$. The current curves mentioned above proved that the negative sequence control loop which contains integral SMC can compensate unbalance current caused by unbalanced load and has a better robustness against internal disturbances than the traditional SMC.
Figure 7 shows the reactive power compensation effect of D-STATCOM when power supply was unbalance. The reactive power compensation effect of the ISMC is shown in Figure 7(a), where Q_grid and Q_DSTATCOM were quickly stable after a small fluctuation when the degree of unbalance in power supply became $5 \%$ at $1.5 \mathrm{~s}$ and $10 \%$ at $1.7 \mathrm{~s}$, and V_pcc was kept at $10.0 \mathrm{kV}$ all along, while the reactive power compensation effect of the traditional SMC is shown in Figure 7(b), where the overshoot is larger than the ISMC. This proved that the positive sequence control loop which contains integral SMC can compensate reactive power needed by load and has a better robustness against power supply unbalance than the traditional SMC.

Figure 8 shows the negative sequence current compensation effect of D-STATCOM when power supply was unbalance. The unbalance compensation effect of the ISMC when the degree of unbalance became $5 \%$ at $1.5 \mathrm{~s}$ is shown in Figure $8(\mathrm{a})$, where the three-phase grid current balanced again at $1.55 \mathrm{~s}$ with smooth transient process and $I_{a_{\text {-grid }}}=$ $1.733 \mathrm{kA}, I_{b_{\text {-grid }}}=1.732 \mathrm{kA}, I_{c_{\text {-grid }}}=1.732 \mathrm{kA}$, and $\Delta I_{s} \%=$ $0.058 \%$, while the unbalance effect of the traditional SMC is shown in Figure $8(\mathrm{~b})$, where $I_{a_{\text {ggrid }}}=1.729 \mathrm{kA}, I_{b_{\text {_grid }}}=$ $1.737 \mathrm{kA}, I_{c_{-} \text {grid }}=1.731 \mathrm{kA}$, and $\Delta I_{s} \%=0.46 \%$. The unbalance compensation effect of the ISMC when the degree of unbalance became $10 \%$ at $1.7 \mathrm{~s}$ is shown in Figure $8(\mathrm{c})$, where the three-phase grid current balanced again at $1.75 \mathrm{~s}$ with smooth transient process and $I_{a_{\text {grid }}}=1.736 \mathrm{kA}$, $I_{b_{\text {_grid }}}=1.737 \mathrm{kA}, I_{c_{\text {_grid }}}=1.739 \mathrm{kA}$, and $\Delta I_{s} \%=0.17 \%$, while the unbalance compensation effect of the traditional SMC is shown in Figure $8(\mathrm{~d})$, where $I_{a_{- \text {grid }}}=1.743 \mathrm{kA}$, 


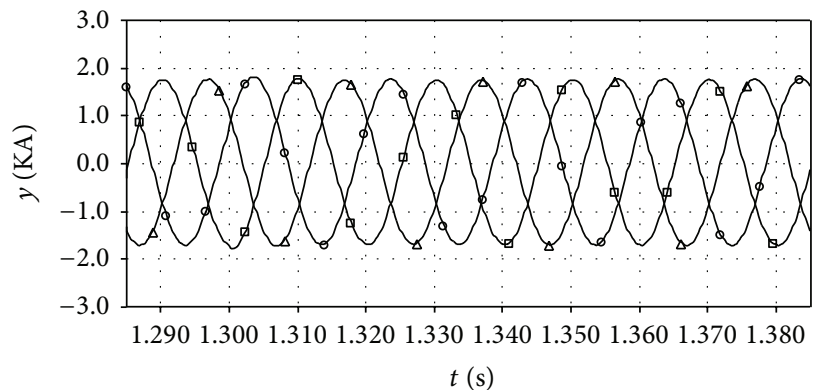

(a)

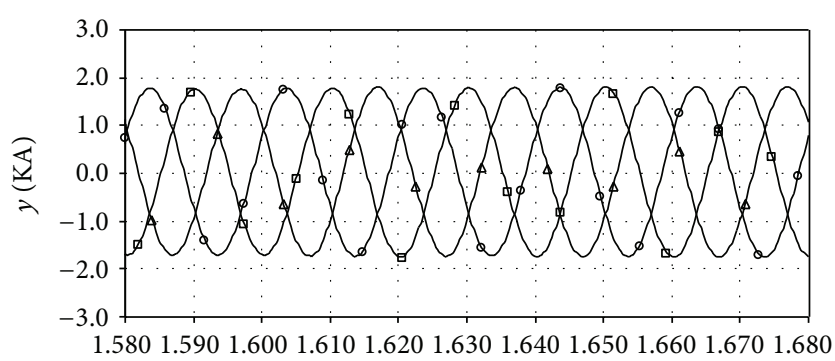

$t$ (s)

$\circ I_{a_{\text {_grid }}}$
$\square I_{b_{\text {_grid }}}$
$\Delta I_{c_{\text {_grid }}}$

(c)

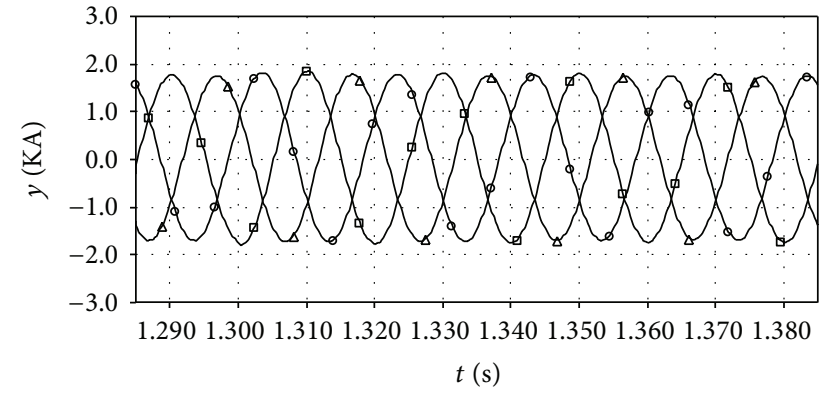

(b)

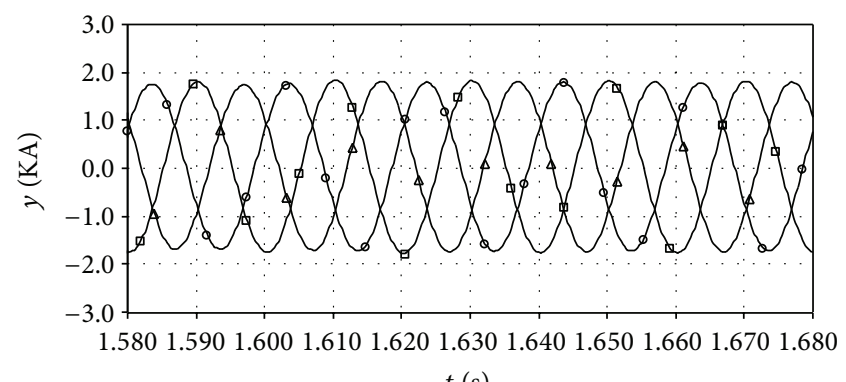

$\begin{array}{ll} & I_{\text {a-grid }} \\ \square & I_{b-\text { grid }} \\ \Delta & I_{c-\text { grid }}\end{array}$

FIGURE 6: The negative sequence current compensation effect of D-STATCOM under internal disturbances.
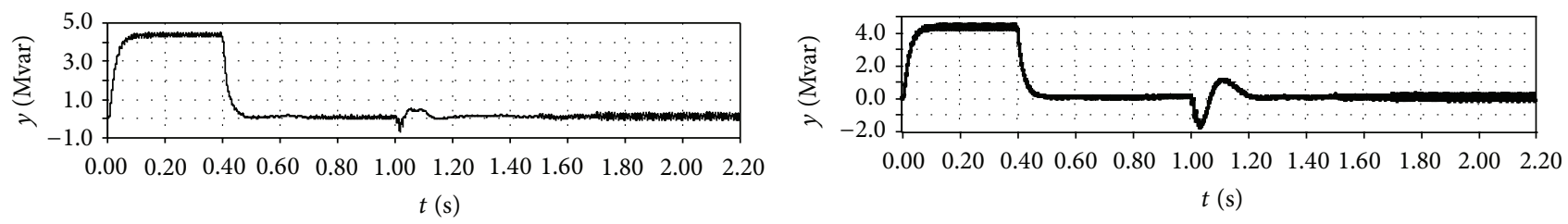

- Q_grid

- Q_grid

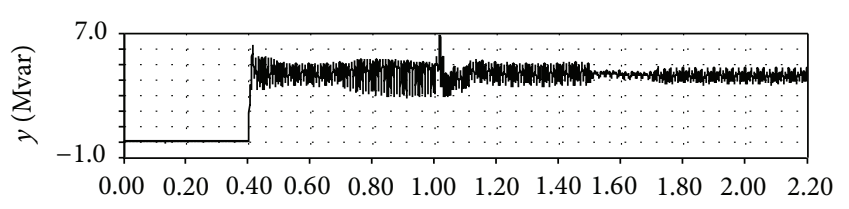

$t(\mathrm{~s})$

\section{- Q_DSTATCOM}

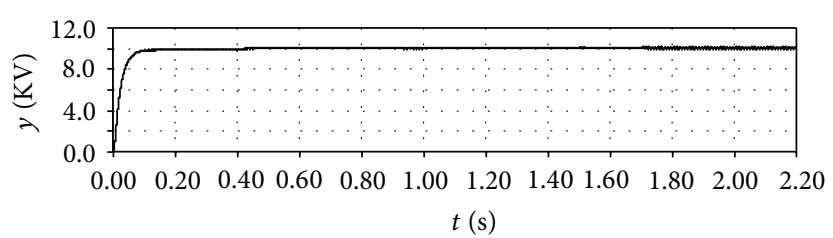

- V_pcc

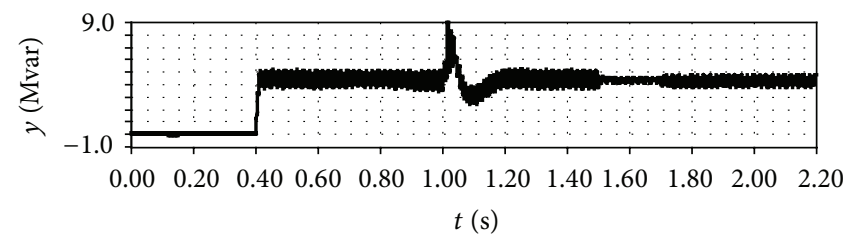

- Q_DSTATCOM

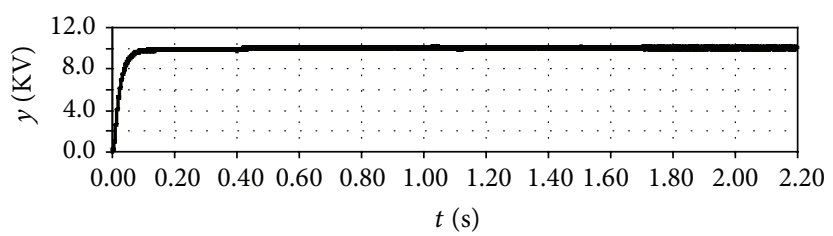

- V_pcc

(a)

(b)

FIGURE 7: The reactive power compensation effect of D-STATCOM when power supply was unbalanced. 


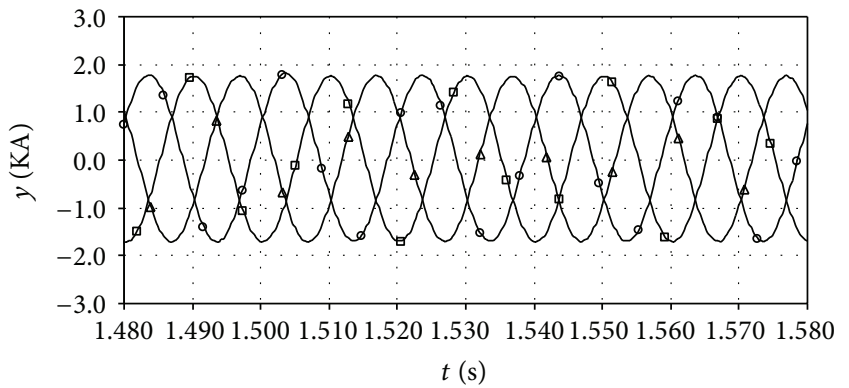

(a)

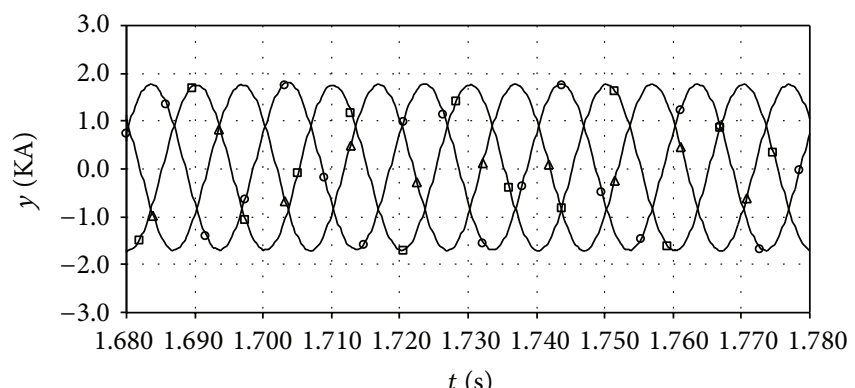

- $I_{a_{\text {ggrid }}}$

- $I_{b_{\text {_grid }}}$

$\Delta I_{c \text {-grid }}$

(c)

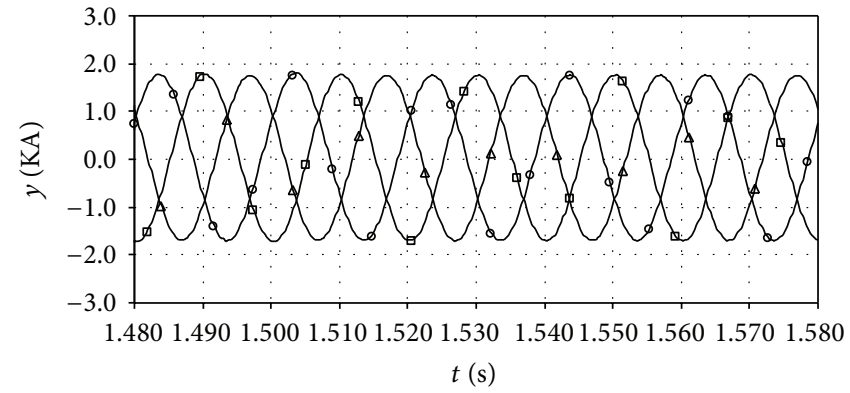

(b)

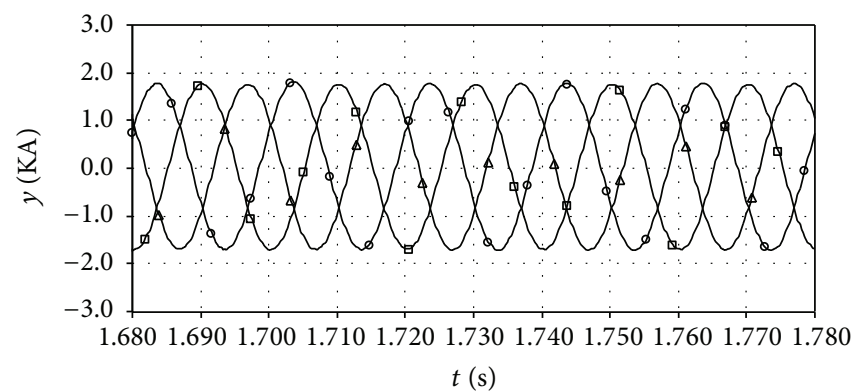

- $I_{a_{\text {_grid }}}$

- $I_{b_{\text {_grid }}}$

$\Delta I_{c \text {-grid }}$

FIGURE 8: The negative sequence current compensation effect of D-STATCOM when power supply was unbalanced.
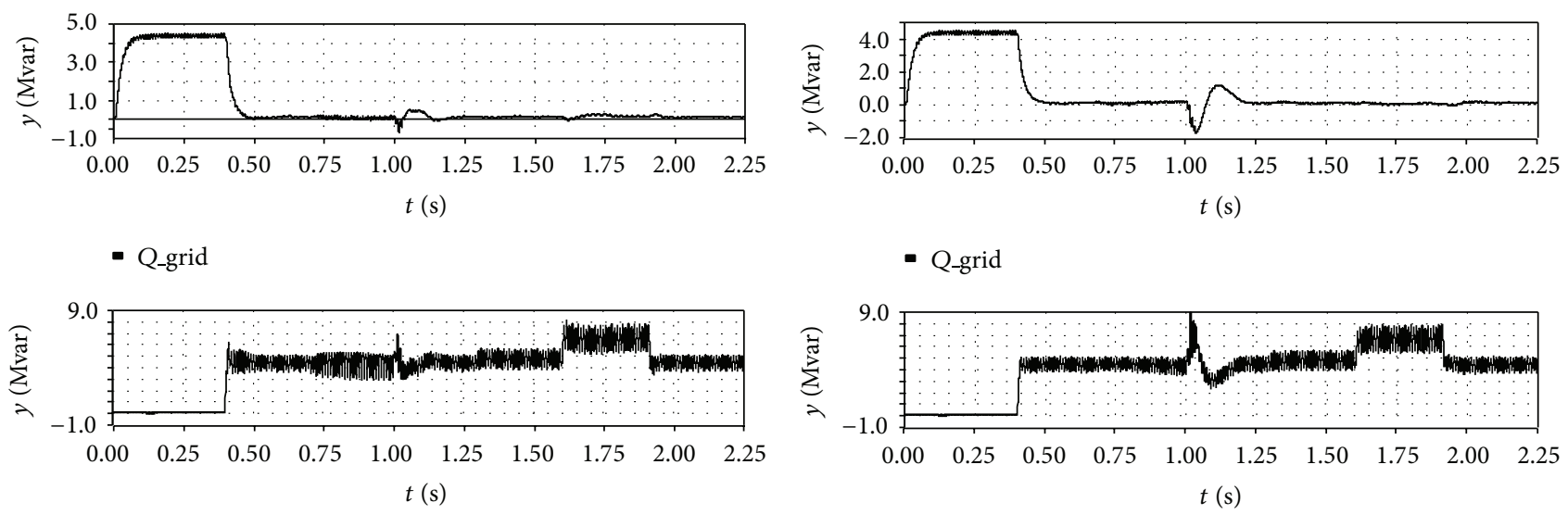

- Q_DSTATCOM

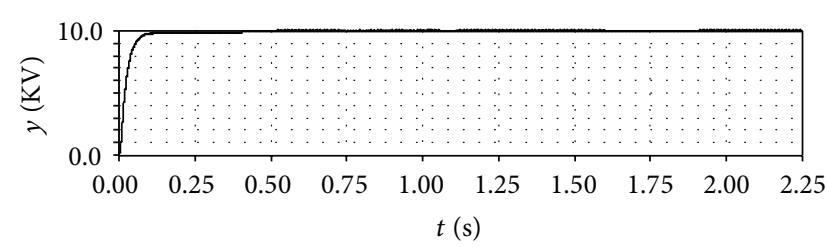

- V_pcc

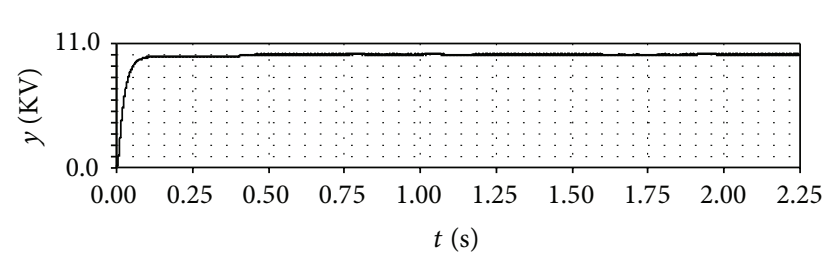

- V_pcc

(a)

(b)

FIGURE 9: The reactive power compensation effect of D-STATCOM under load variation. 


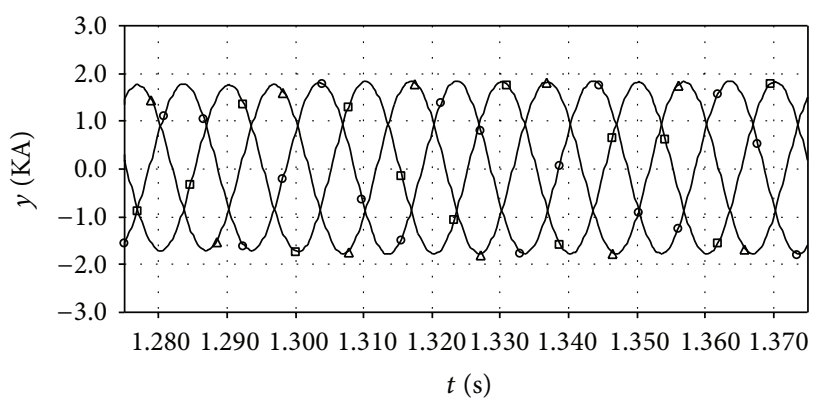

(a)

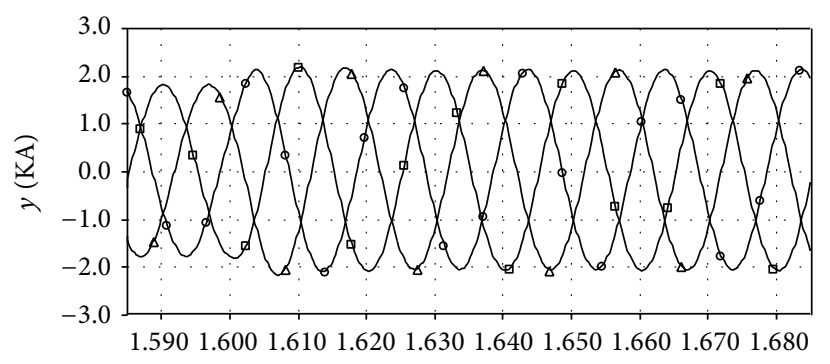

$t(\mathrm{~s})$

(c)

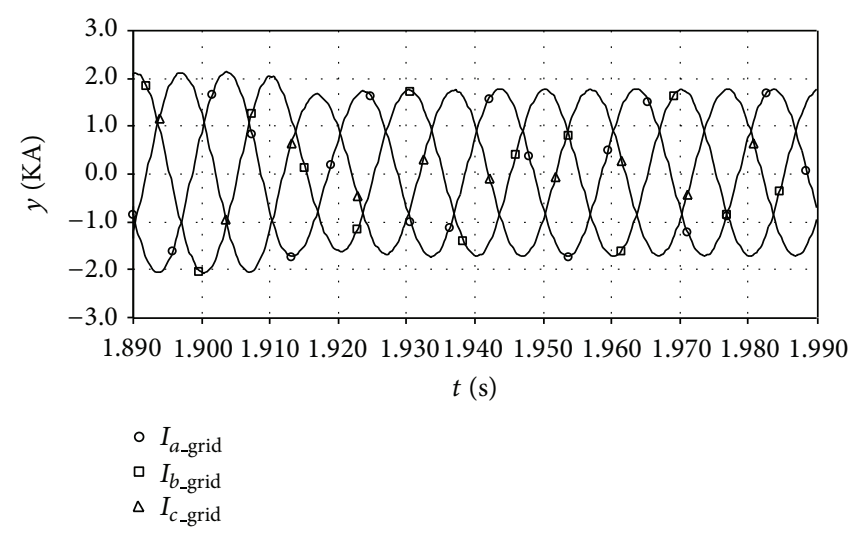

(e)

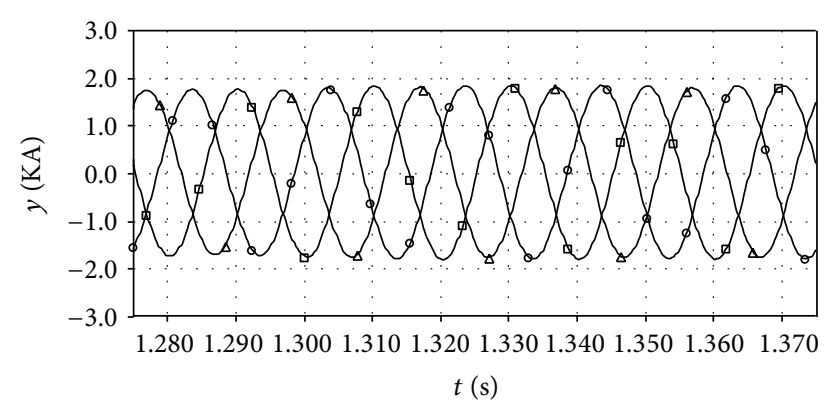

(b)

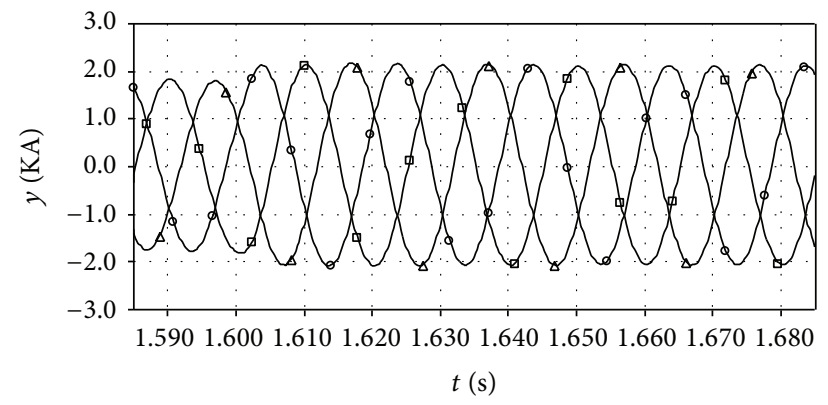

(d)

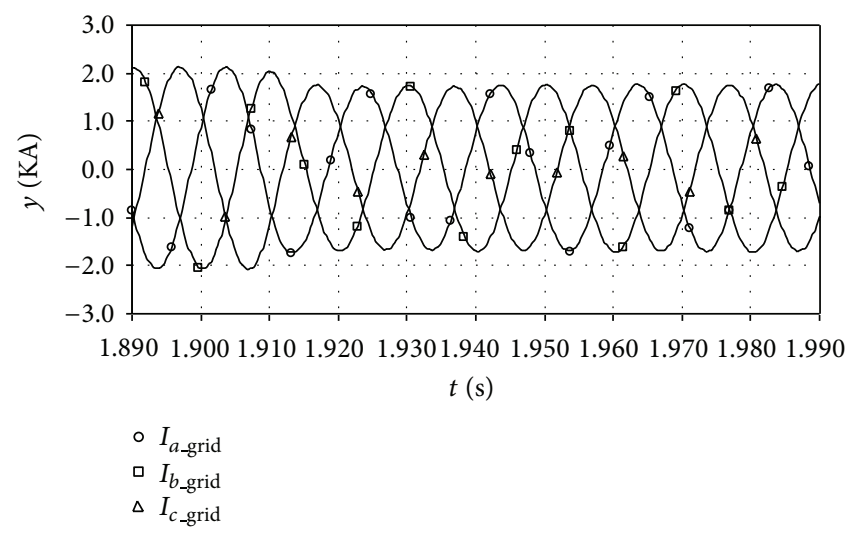

(f)

FIGURE 10: The negative sequence current compensation effect of D-STATCOM under load variation.

$I_{b_{\text {grid }}}=1.727 \mathrm{kA}, I_{c_{\text {_grid }}}=1.740 \mathrm{kA}$, and $\Delta I_{s} \%=0.92 \%$. The current curves above proved that the negative sequence control loop which contains integral SMC can compensate unbalance current caused by unbalanced load and has a better robustness against power supply unbalance than the traditional SMC.

Figure 9 shows the reactive power compensation effect of D-STATCOM during load variation. The reactive power compensation effect of the ISMC is shown in Figure 9(a), where Q_grid and Q_DSTATCOM were quickly stable after a small fluctuation when load variation happened at $1.3 \mathrm{~s}$, $1.6 \mathrm{~s}$ and $1.9 \mathrm{~s}$, and V_pcc was kept at $10.0 \mathrm{kV}$ all along, while the reactive compensation effect of the traditional SMC is shown in Figure 9(b), where the overshoot is larger than the ISMC. This proved that the positive sequence control loop which contains integral SMC can compensate reactive power needed by load and has a good robustness against load variation.

Figure 10 shows the negative sequence current compensation effect of D-STATCOM when load variation. The unbalance compensation effect of the ISMC when load in phase $B$ became $4+j 0.003$ and load in phases $A$ and $C$ remained unchanged at $1.3 \mathrm{~s}$ is shown in Figure 10(a), where the three- phase grid current balanced again at $1.35 \mathrm{~s}$ with smooth transient process and $I_{a_{\text {_grid }}}=1.801 \mathrm{kA}, I_{b_{\text {_grid }}}=$ $1.799 \mathrm{kA}, I_{c_{\text {_grid }}}=1.800 \mathrm{kA}$, and $\Delta I_{s} \%=0.11 \%$, while the unbalance compensation effect of the traditional SMC is shown in Figure $10(\mathrm{~b})$, where $I_{a_{\text {_grid }}}=1.810 \mathrm{kA}, I_{b_{\text {-grid }}}=$ $1.817 \mathrm{kA}, I_{c_{-} \text {grid }}=1.773 \mathrm{kA}$, and $\Delta I_{s} \%=2.43 \%$. The unbalance compensation effect of the ISMC when load in phase $A$ and $B$ became $3+j 0.003$ and $4+j 0.003$ and load in phase $C$ remained unchanged at $1.6 \mathrm{~s}$ is shown in Figure 10(c), 

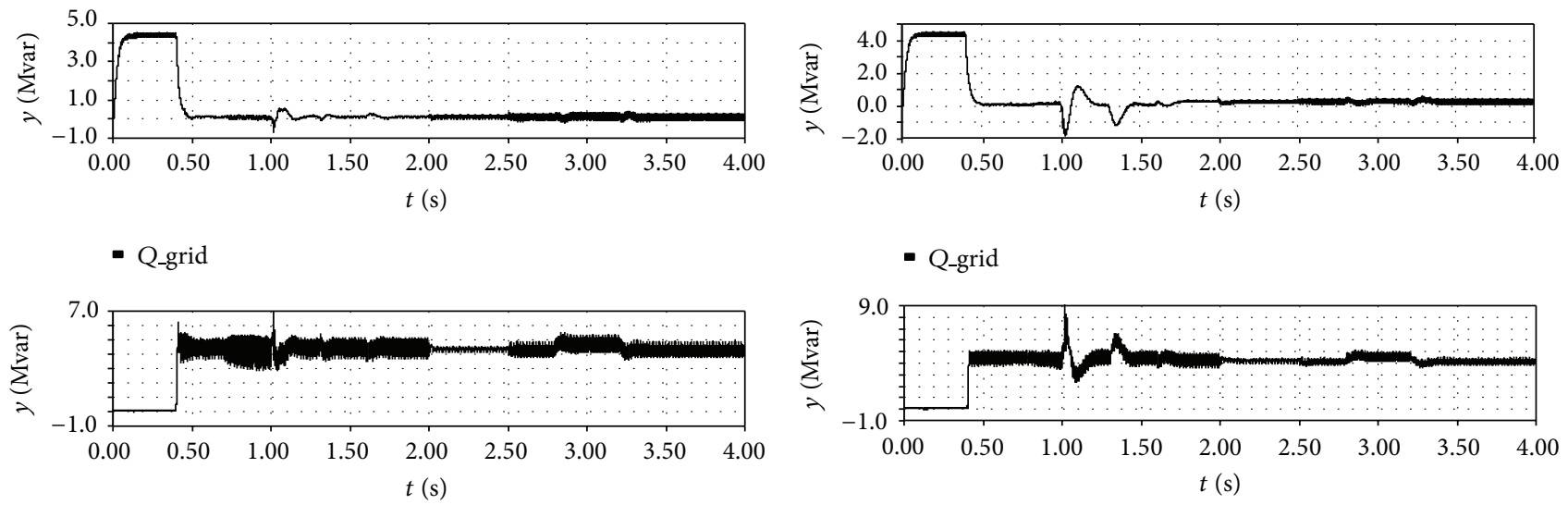

- QDDSTATCOM
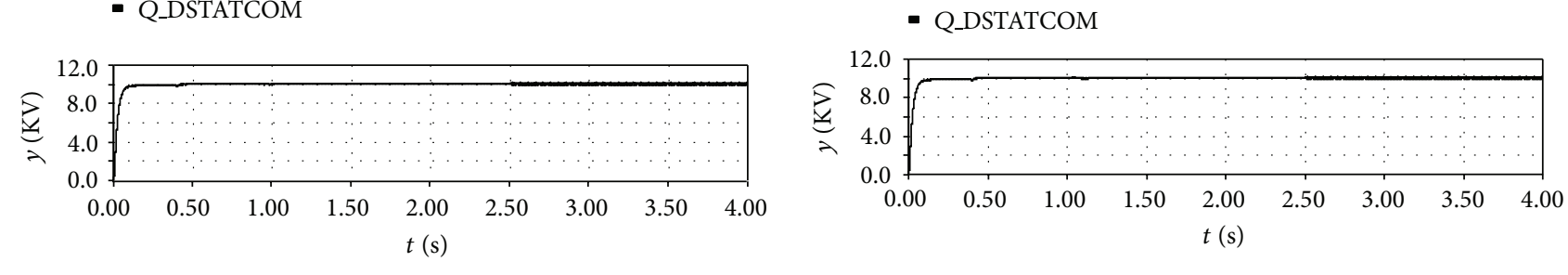

- V_pcc

- $V_{-p c c}$

(a)

(b)

FIGURE 11: The reactive power compensation effect of D-STATCOM under internal and external disturbances.

where the three-phase grid current balanced again at $1.66 \mathrm{~s}$ with smooth transient process and $I_{a_{- \text {grid }}}=2.090 \mathrm{kA}$, $I_{b_{\text {-grid }}}=2.091 \mathrm{kA}, I_{c_{\text {-grid }}}=2.092$, and $\Delta I_{s} \%=0.096 \%$, while the unbalance compensation effect of the traditional SMC is shown in Figure $10(\mathrm{~d})$, where $I_{a_{\text {-grid }}}=2.086 \mathrm{kA}, I_{b_{\text {_grid }}}=$ $2.084 \mathrm{kA}, I_{c_{\text {-grid }}}=2.106$, and $\Delta I_{s} \%=1.05 \%$. The unbalance compensation effect of the ISMC when load in the threephase restored to the original value at $1.9 \mathrm{~s}$ is shown in Figure 10(e), where the three-phase grid current balanced again at $1.96 \mathrm{~s}$ with smooth transient process and $I_{a_{\text {_grid }}}=$ $1.738 \mathrm{kA}, I_{b_{\text {_grid }}}=1.737 \mathrm{kA}, I_{c_{-} \text {grid }}=1.737 \mathrm{kA}$, and $\Delta I_{s} \%=$ $0.058 \%$. The unbalance compensation effect of the traditional $\mathrm{SMC}$ is shown in Figure $10(\mathrm{f})$ where $I_{a_{\text {grid }}}=1.735 \mathrm{kA}$, $I_{b_{\text {-grid }}}=1.752 \mathrm{kA}, I_{c_{\text {-grid }}}=1.722 \mathrm{kA}$, and $\Delta I_{s} \%=1.73 \%$. The current curves above proved that the negative sequence control loop which contains integral SMC can compensate unbalance current caused by unbalanced load and has a better robustness against load variation than the traditional SMC.

Figure 11 shows the reactive power compensation effect of D-STATCOM under internal disturbances containing parameter variation happened at $1.3 \mathrm{~s}$, joint impedance variation happened at $1.6 \mathrm{~s}$, external disturbances containing power supply unbalance happened at $2.0 \mathrm{~s}$ and $2.5 \mathrm{~s}$, and load variation happened at $2.8 \mathrm{~s}$ and $3.2 \mathrm{~s}$. The reactive power compensation effect of the ISMC is shown in Figure 11(a) where Q_grid and Q_DSTATCOM were quickly stable after a small fluctuation, and $V_{-}$pcc was kept at 10.0 Mvar all along under internal and external disturbances, while the reactive power compensation effect of the traditional SMC is shown in Figure 11(b), where the overshoot is larger than the ISMC.
This proved that the positive sequence control loop which contains integral SMC can compensate the reactive power needed by load and has a better robustness against internal and external disturbances than the traditional SMC.

Figure 12 shows the negative sequence current compensation effect of D-STATCOM under internal and external disturbances. The DC voltage controlled by the ISMC is shown in Figure 12(a), where all DC voltages were stable at $1 \mathrm{kV}$ under internal and external disturbances. This is the basis of the normal operation. The unbalance compensation effect of the ISMC is shown in Figure 12(b), where the negative sequence current generated by D-STATCOM could track the negative sequence current in load to make negative sequence current in grid keep at $0.0 \mathrm{kA}$ under internal and external disturbances, while the unbalance compensation effect of the traditional SMC is shown in Figure 12(c), where the negative sequence current generated by D-STATCOM could not track the negative sequence current in load precisely. The final wave form of three-phase current controlled by the ISMC is shown in Figure $12(\mathrm{~d})$, where $I_{a_{\text {_grid }}}=1.768 \mathrm{kA}, I_{b_{\text {-grid }}}=$ $1.769 \mathrm{kA}, I_{c_{-} \text {grid }}=1.769 \mathrm{kA}$, and $\Delta I_{s} \%=0.057 \%$, while the final wave form of the three-phase current controlled by the traditional SMC is shown in Figure 12(e), where $I_{a_{\text {-grid }}}=1.787 \mathrm{kA}, I_{b_{\text {_grid }}}=1.739 \mathrm{kA}, I_{c_{\text {-grid }}}=1.757 \mathrm{kA}$, and $\Delta I_{s} \%=2.73 \%$. The current curves above proved that the negative sequence control loop which contains the ISMC can compensate unbalance current caused by unbalanced load and has a better robustness against internal and external disturbances than the traditional SMC. 


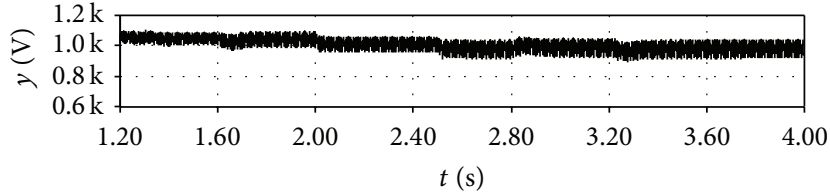

- $V_{d c a \_a v e}$

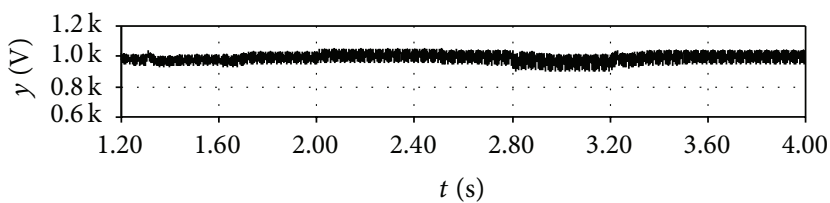

- $V_{d c b \text { ave }}$

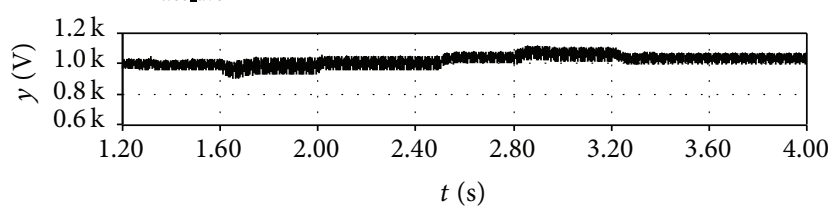

- $V_{d c c_{-} \text {ave }}$

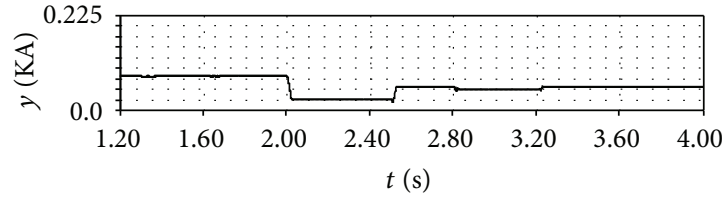

- The negative sequence current in load

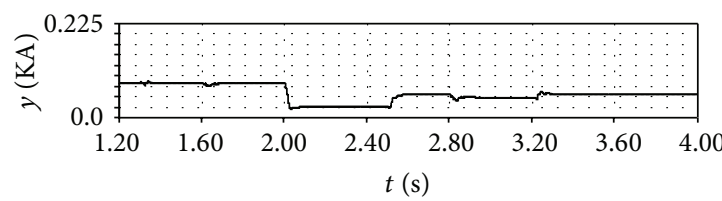

- The negative sequence current generated by D-STATCOM

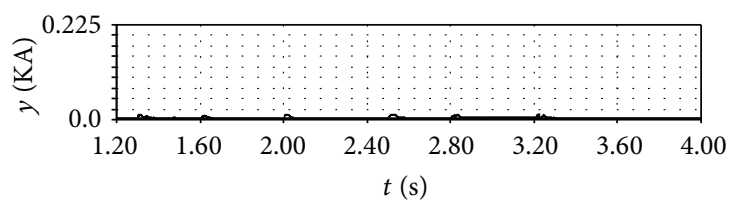

- The negative sequence current in grid

(b)

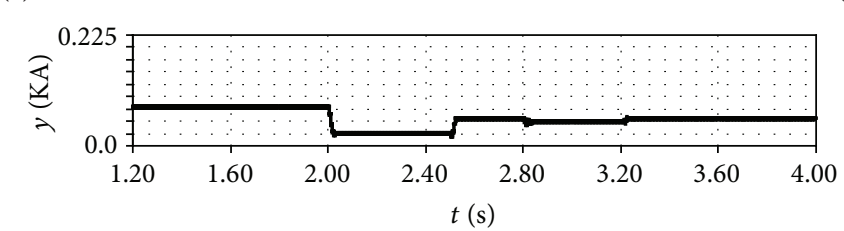

- The negative sequence current in load

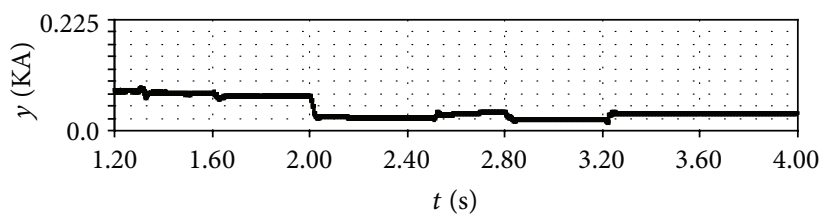

- The negative sequence current generated by D-STATCOM

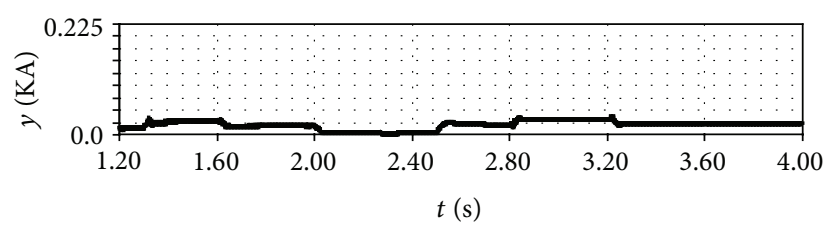

- The negative sequence current in grid

(c)

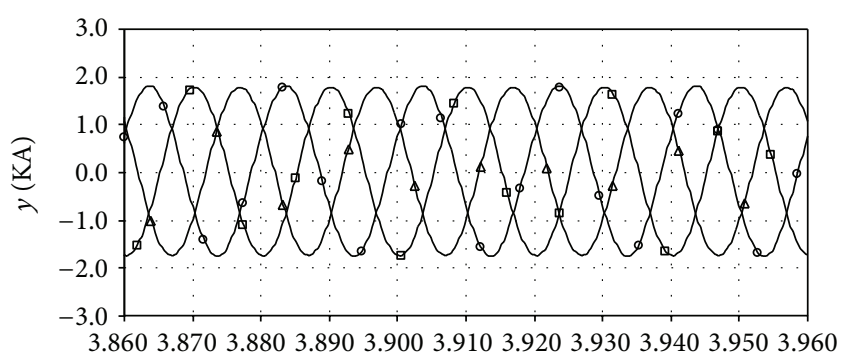

$t(\mathrm{~s})$

$$
\begin{array}{ll}
\circ & I_{a_{\text {ggrid }}} \\
\square & I_{b_{\text {_grid }}}
\end{array}
$$

(d)

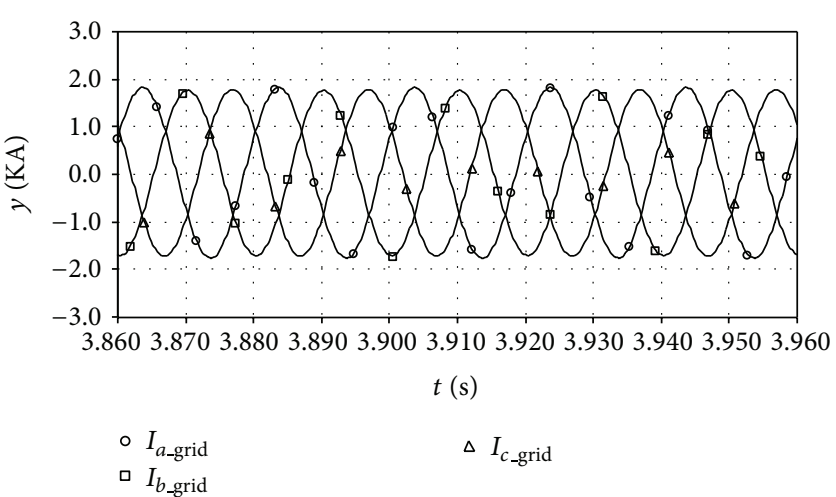

(e)

FIGURE 12: The negative sequence current compensation effect of D-STATCOM under internal and external disturbances. 


\section{Conclusions}

Considering that D-STATCOM is a nonlinear and strong coupling system and the impact caused by unbalanced load on D-STATCOM and grid, a two-loop control strategy based on the input-output feedback linearization and the integral sliding mode technique was applied to D-STATCOM for unbalanced load compensation. The positive and negative sequence separation technique were used to divide the control strategy into positive sequence control loop for the positive reactive power compensation and negative sequence control loop for unbalance compensation. The combination of input-output feedback linearization and integral sliding mode control was used in the two loops to strengthen the tracking capacity and robustness against the internal and external disturbances. The simulation results demonstrated that the control strategy can simultaneously compensate the reactive power and negative sequence current caused by unbalanced load to improve the power quality and has a good robustness against internal and external disturbances. Moreover, the design of the integral sliding mode control compensator was straightforward.

\section{Conflict of Interests}

The authors declare that there is no conflict of interests regarding the publication of this paper.

\section{Acknowledgment}

The authors gratefully acknowledge the support of the Fundamental Research Funds for the Central Universities of China for the financial support under Grant no. 2012JBM098.

\section{References}

[1] G. F. Reed, J. E. J. Greaf, T. M. Matsumoto et al., "Application of a $5 \mathrm{MVA}, 4.16 \mathrm{kV}$ D-STATCOM system for voltage flicker compensation at Seattle iron \& metals," in Proceedings of the Power Engineering Society Summer Meeting, pp. 1605-1611, Seattle, Wash, USA, July 2000.

[2] F. Juntao, Z. Shenglei, and Z. Jian, "Adaptive sliding mode control of single-phase shunt active power filter," Mathematical Problems in Engineering, vol. 2012, Article ID 809187, 22 pages, 2012.

[3] J. Lian and J. Zhao, "Adaptive variable structure control for uncertain switched delay systems," Circuits, Systems, and Signal Processing, vol. 29, no. 6, pp. 1089-1102, 2010.

[4] Y.-J. Huang, T.-C. Kuo, and S.-H. Chang, "Adaptive slidingmode control for nonlinear systems with uncertain parameters," IEEE Transactions on Systems, Man, and Cybernetics B, vol. 38, no. 2, pp. 534-539, 2008.

[5] C. W. Tao, M.-L. Chan, and T.-T. Lee, "Adaptive fuzzy sliding mode controller for linear systems with mismatched timevarying uncertainties," IEEE Transactions on Systems, Man, and Cybernetics B, vol. 33, no. 2, pp. 283-294, 2003.

[6] M. Chen, R. Mei, and B. Jiang, "Sliding mode control for a class of uncertain MIMO nonlinear systems with application to nearspace vehicles," Mathematical Problems in Engineering, vol. 2013, Article ID 180589, 9 pages, 2013.
[7] S. Li, Z. Wang, and G. Wang, "Proportional-integral-differential neural network based sliding-mode controller for modular multi-level high-voltage DC converter of offshore wind power," Electric Power Components and Systems, vol. 41, no. 4, pp. 427446, 2013.

[8] D. Xu, B. Jiang, M. Qian, and J. Zhao, "Terminal sliding mode control using adaptive fuzzy-neural observer," Mathematical Problems in Engineering, vol. 2013, Article ID 958958, 8 pages, 2013.

[9] H. Sira-Ramírez, A. Luviano-Juárez, and J. Cortés-Romero, "Robust input-output sliding mode control of the buck converter," Control Engineering Practice, vol. 21, no. 5, pp. 671-678, 2013.

[10] Z. Chen, B. Cong, and X. Liu, "Switching gain reduction in adaptive sliding mode control for rigid spacecraft attitude maneuvers," Mathematical Problems in Engineering, vol. 2013, Article ID 602869, 9 pages, 2013.

[11] J. Komsta, N. van Oijen, and P. Antoszkiewicz, "Integral sliding mode compensator for load pressure control of die-cushion cylinder drive," Control Engineering Practice, vol. 21, no. 5, pp. 708-718, 2013.

[12] Q. Zong, Z. Zhao, L. Doll, and L. Sun, "Integral sliding mode control for a class of nonlinear mismatched uncertain systems," in Proceedings of the 2nd International Symposium on Systems and Control in Aerospace and Astronautics (ISSCAA '08), Shenzhen, China, December 2008.

[13] J. Lian, J. Zhao, and G. M. Dimirovski, "Integral sliding mode control for a class of uncertain switched nonlinear systems," European Journal of Control, vol. 16, no. 1, pp. 16-22, 2010.

[14] M. Liu, P. Shi, L. Zhang, and X. Zhao, "Fault-tolerant control for nonlinear markovian jump systems via proportional and derivative sliding mode observer technique," IEEE Transactions on Circuits and Systems I, vol. 58, no. 11, pp. 2755-2764, 2011.

[15] M. Slepchenkov and K. Smedley, "Flicker mitigation and load balancing in steel plants power systems by OCC-hexagram converter based STATCOM," in Proceedings of the IEEE Industry Applications Society Annual Meeting, Houston, Tex, USA, October 2008 .

[16] Q. Song and W. Liu, "Control of a cascade STATCOM with star configuration under unbalanced conditions," IEEE Transactions on Power Electronics, vol. 24, no. 1, pp. 45-58, 2009.

[17] W. Chang and K.-D. Yeh, "Design of D-STATCOM for fast load compensation of unbalanced distribution systems," Power Electronics and Drive Systems, vol. 2, pp. 801-806, 2001.

[18] B. Blažič and I. Papič, "Improved D-Statcom control for operation with unbalanced currents and voltages," IEEE Transactions on Power Delivery, vol. 21, no. 1, pp. 225-233, 2006.

[19] B. Yang, G. Zeng, and Y. Zhong, "Research on the control system of cascaded multilevel STATCOM for unbalanced load compensation," in Proceedings of the IEEE Power Engineering and Automation Conference (PEAM '11), pp. 88-91, Wuhan, China, September 2011.

[20] A. E. Leon, J. M. Mauricio, J. A. Solsona, and A. GomezExposito, "Software sensor-based STATCOM control under unbalanced conditions," IEEE Transactions on Power Delivery, vol. 24, no. 3, pp. 1623-1632, 2009.

[21] X. Sun and W. Wu, "A new sliding mode control of STATCOM and its effects on wind farm," in Proceedings of the International Conference on Electronic and Mechanical Engineering and Information Technology (EMEIT '11), pp. 2938-2941, Harbin, China, August 2011. 
[22] C.-H. Shan, B. Wang, D. Chen, B.-F. Qian, and X.-H. Zhang, "Study of the reactive compensation of STATCOM based on the sliding mode control theory," Power System Protection and Control, vol. 38, no. 18, pp. 150-154, 2010.

[23] D.-Z. Jiang and Z.-H. Zhang, "Control scheme of three-phase H-bridge cascaded STATCOM," High Voltage Engineering, vol. 37, no. 8, pp. 2024-2031, 2011.

[24] H.-C. Tsai and C.-C. Chu, "Nonlinear STATCOM controller using passivity-based sliding mode control," in Proceedings of the IEEE Asia Pacific Conference on Circuits and Systems, pp. 1996-1999, Singapore, December 2006.

[25] M. A. Eldery, E. F. El-Saadany, and M. M. A. Salama, "Sliding mode controller for pulse width modulation based DSTATCOM," in Proceedings of the Canadian Conference on Electrical and Computer Engineering (CCECE '06), pp. 2216-2219, Ottawa, Canada, May 2006.

[26] F. Rong, A. Luo, C. Tu, and J. Ou, "Application of variable structure space vector control in STATCOM," Transactions of China Electrotechnical Society, vol. 22, no. 12, pp. 128-139, 2007.

[27] Y. Zhou, A Study on DC Capacitor Voltage Control Strategy of Cascade STATCOM, Beijing Jiao Tong University, Beijing, China, 2012. 


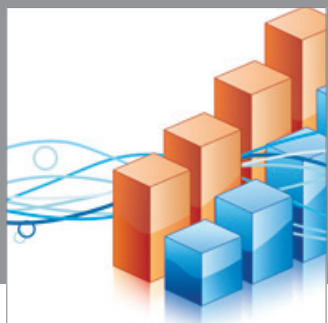

Advances in

Operations Research

mansans

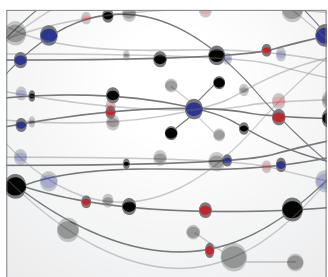

The Scientific World Journal
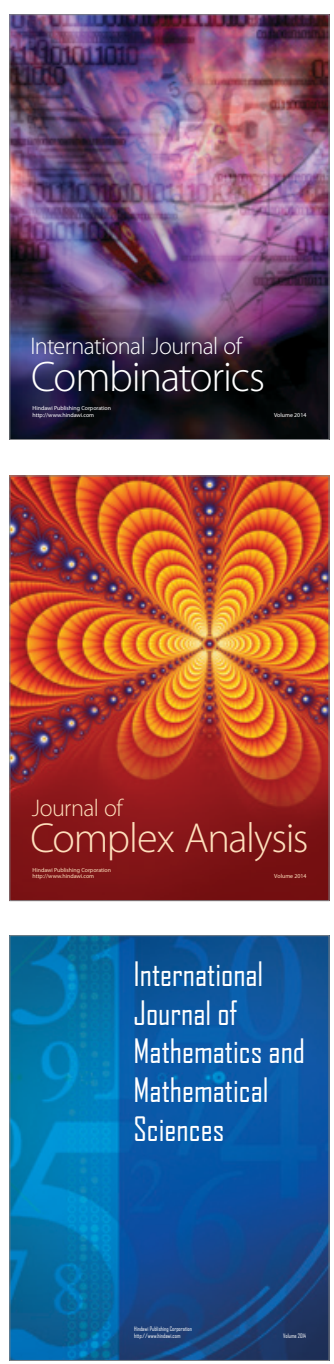
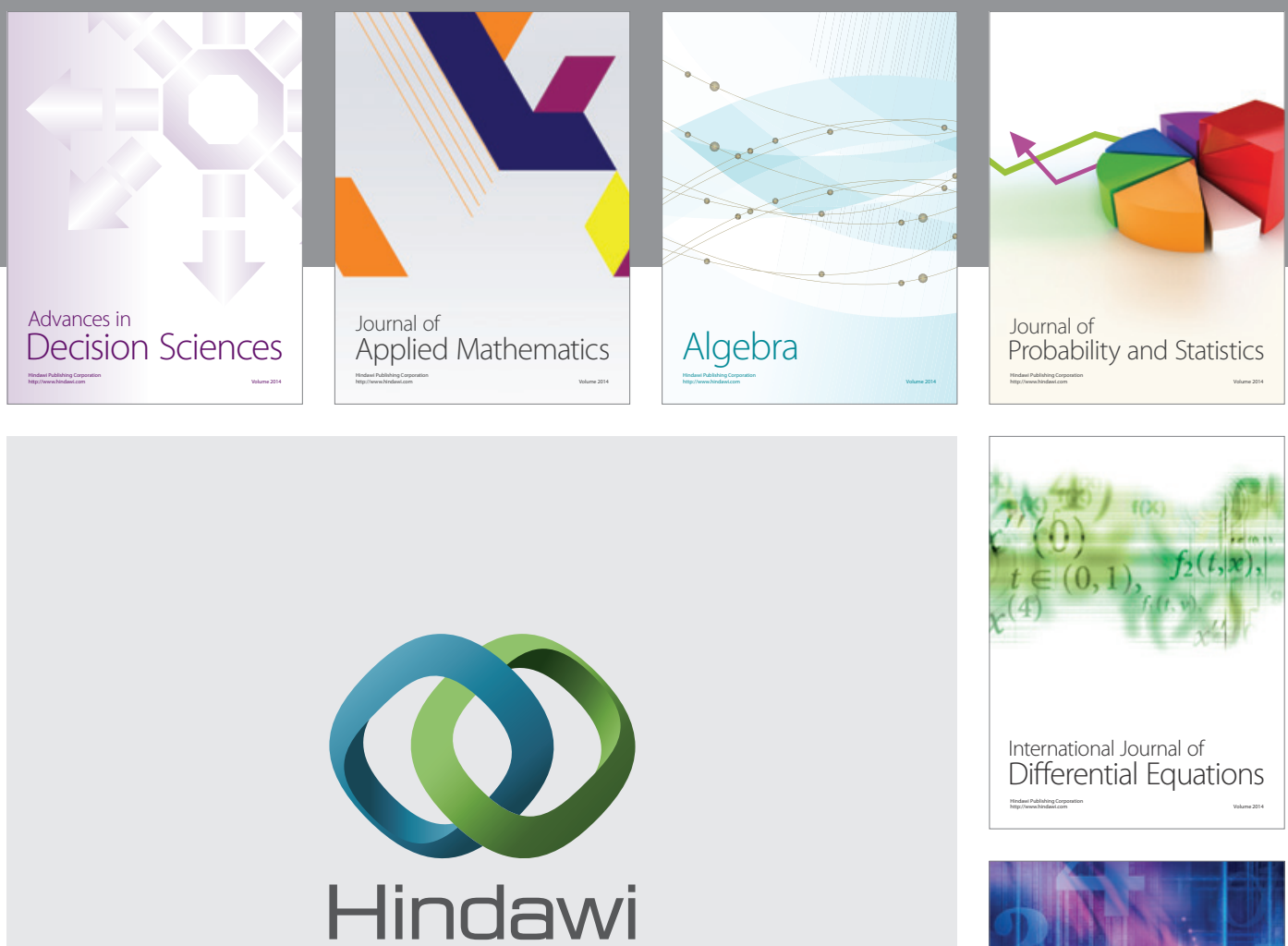

Submit your manuscripts at http://www.hindawi.com
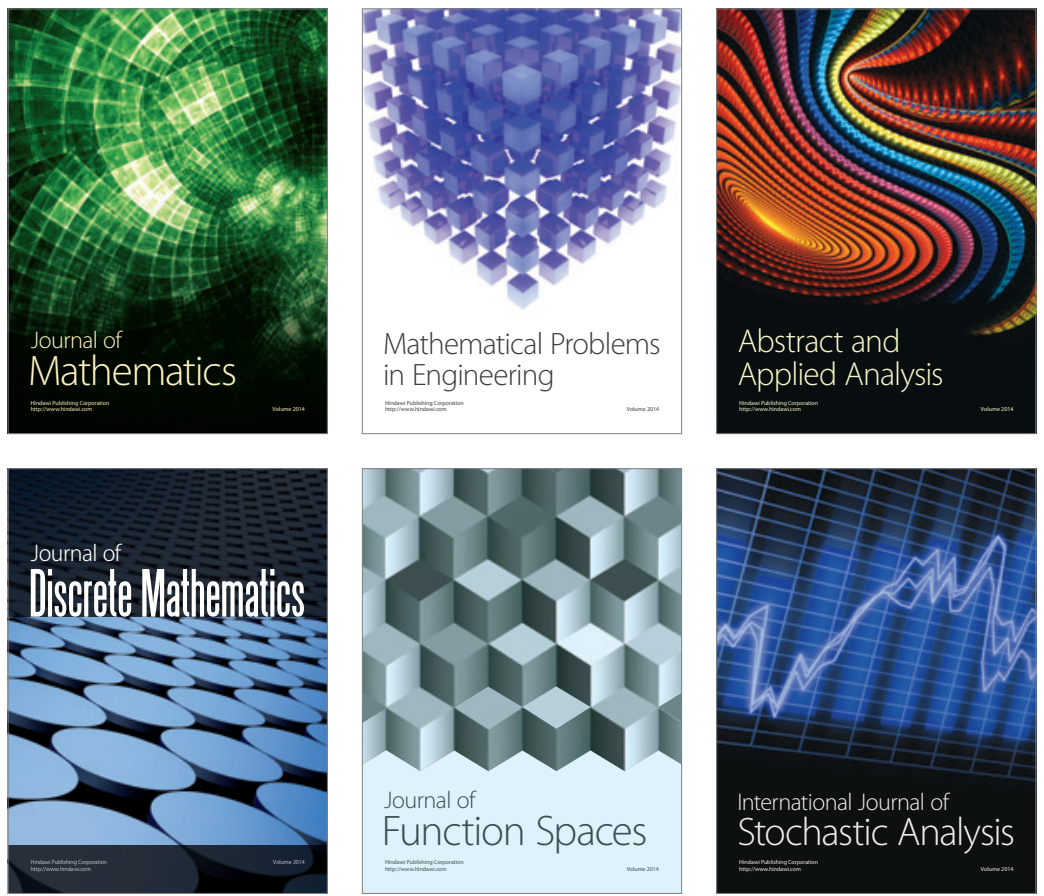

Journal of

Function Spaces

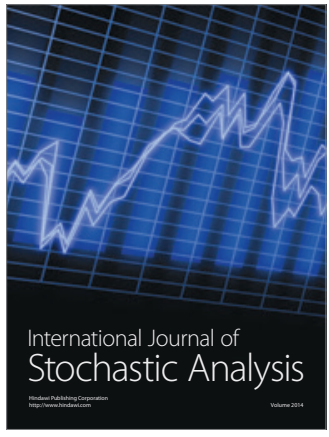

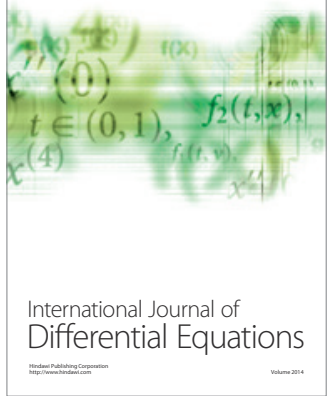
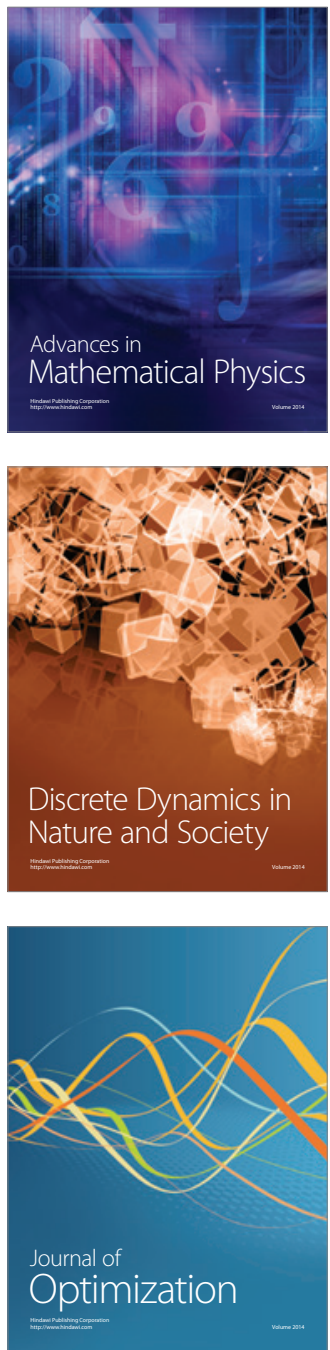